\title{
CLASSIFICATION OF ANAEROBIC DIGESTERS
}

by

\author{
Shabari Lnu \\ B.Eng., Dayanand Sagar College \\ of Engineering, Bengaluru, \\ India 2017
}

\author{
A report \\ presented to Ryerson University \\ in partial fulfillment of the \\ requirements for the degree of \\ Master of Engineering \\ in the Program of \\ Civil Engineering
}

Toronto, Ontario, Canada, 2019

CShabari Lnu, 2019 


\section{AUTHOR'S DECLARATION}

\section{AUTHORS DECLARATION FOR ELECTRONIC SUBMISSION OF A THESIS}

I hereby declare that I am the sole author of this thesis. This is a true copy of the thesis, including any required final revisions, as accepted by my examiners.

I authorize Ryerson University to lend this thesis to other institution or individuals for the purpose of scholarly research.

I further authorize Ryerson University to produce this thesis by photocopying or by other means, in total or in part, at the request of other institution or individuals for the purpose of scholarly research.

I understand that my thesis may be made electronically available to the public. 


\author{
Classification of Anaerobic Digesters \\ Master of Engineering, Civil Engineering, 2019 \\ Shabari Lnu, Ryerson University
}

\begin{abstract}
Anaerobic digestion technology is one of the emerging and very effective mode of treating the waste in the production of renewable energy. In the present world with the increase in pollution and mankind there is very much necessity for the renewable energy. In this classification system the anaerobic digesters are grouped depend on the various factors like temperature, feeding mode, solid content, number of stages, organic loading rate and biomass. There are several Fullscale case studies on anaerobic digestion technology of different parts on the globe included in the report. The potential is very well examined and explained on how important and better is the method of anaerobic digestion for the treatment of waste with production and utilization of energy which is produced by the waste treated.
\end{abstract}




\section{Acknowledgments}

I would like to show my genuine gratitude and thanks to my supervisor Dr. Elsayed Elbeshbishy who supported and took time out to help me with this project. His guidance, assurance, initiative, and availability to answer all my questions throughout this research enabled me to be enthusiastic about this project; I am very grateful for him. 
Table of Contents

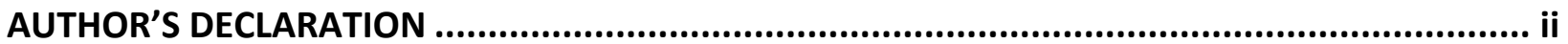

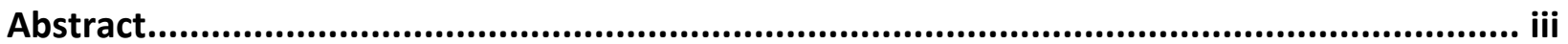

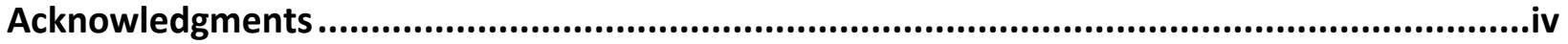

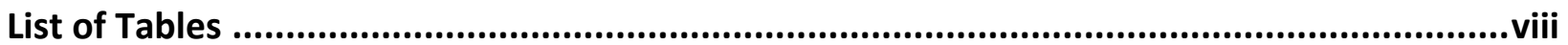

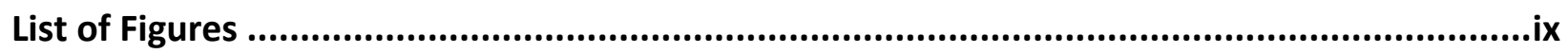

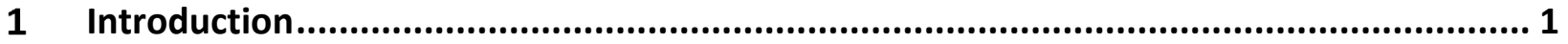

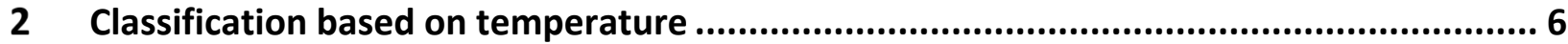

2.1 Mesophilic anaerobic digester.....................................................................6

2.1.1 Advantages of mesophilic anaerobic digesters. ................................................. 7

2.1.2 Disadvantages of mesophilic anaerobic digesters.........................................8

2.2 Thermophilic anaerobic digester .................................................................... 8

2.2.1 Advantages of thermophilic anaerobic digesters: ..........................................9

2.2.2 Disadvantages of thermophilic anaerobic digesters:.....................................10

2.2.3 Full scale adoption of thermophilic digesters at the Christchurch wastewater

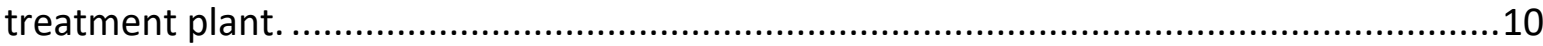

2.2.4 Case study - Linko Gas, Denmark ................................................................12

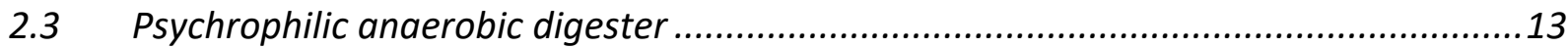

2.3.1 Advantages of psychrophilic anaerobic digesters. ...........................................14

2.3.2 Disadvantages of psychrophilic anaerobic digesters........................................14

3 Classification based on number of stages ............................................................ 14

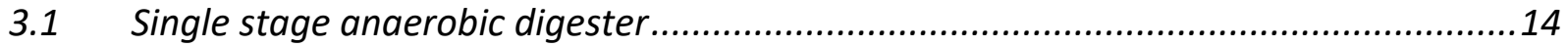

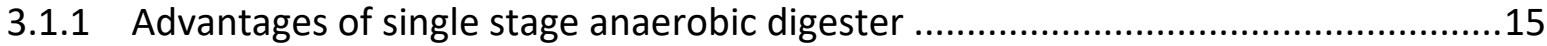

3.1.2 Disadvantages of single stage anaerobic digester ..............................................16

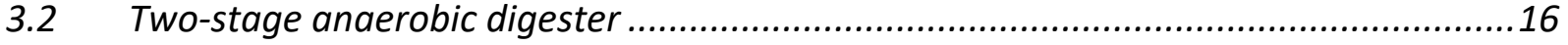

3.2.1 Advantages of two-stage anaerobic system:.................................................18

3.2.2 Disadvantages of two-stage anaerobic system: ..............................................18

4 Classification based on feeding mode ............................................................. 18

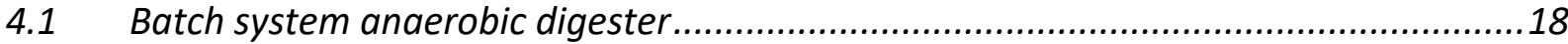

4.1.1 Advantages of batch system anaerobic digester...........................................19

4.1.2 Disadvantages of batch system anaerobic digester ..........................................19

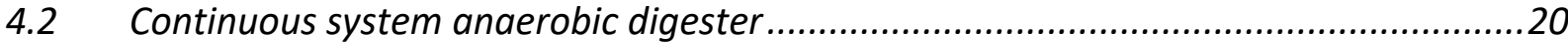

4.2.1 Advantages of continuous system anaerobic digester .......................................21 
4.2.2 Disadvantages of continuous system anaerobic digester ...............................21

5 Classification based on solid content............................................................. 22

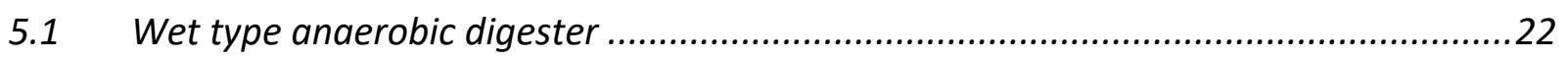

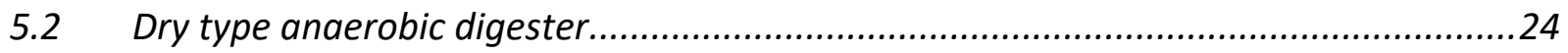

5.2.1 Advantages of dry anaerobic digester .......................................................26

5.2.2 Disadvantages of dry anaerobic digesters ....................................................26

6 Classification based on organic loading rate .......................................................... 26

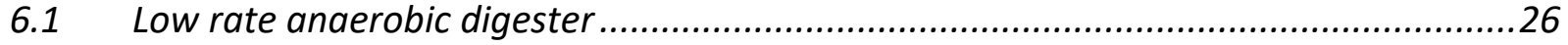

$6.2 \quad$ High rate anaerobic digester ......................................................................27

6.2.1 One stage high rate anaerobic digester............................................................29

6.2.2 Two stage high rate anaerobic digester .....................................................30

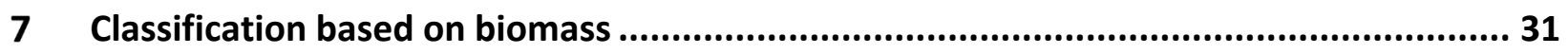

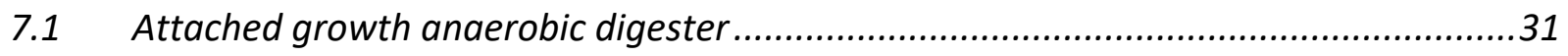

7.1.1 Advantages of attached growth anaerobic digester ..........................................32

7.1.2 Disadvantages of attached growth anaerobic digester ....................................32

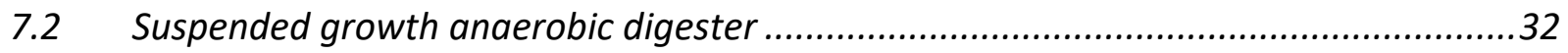

7.2.1 Advantages of suspended growth anaerobic digester ......................................33

7.2.2 Disadvantages of suspended growth anaerobic digester...................................33

8 Different conventional systems of anaerobic digestion technology .............................. 34

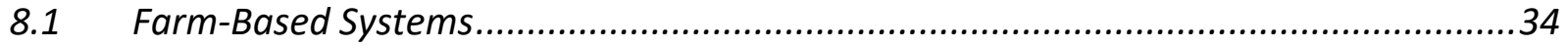

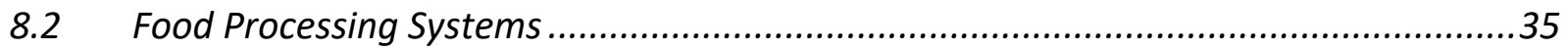

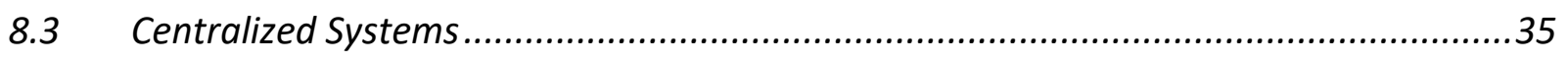

8.4 Examples of most commonly used anaerobic digesters ..........................................35

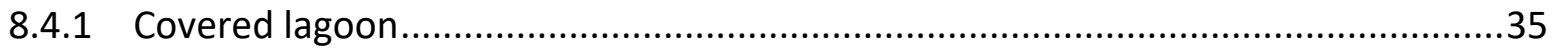

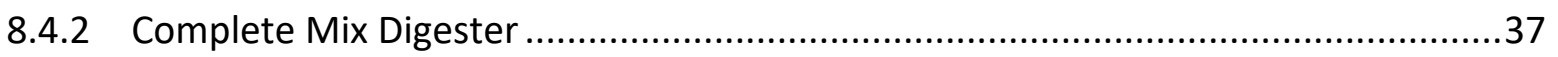

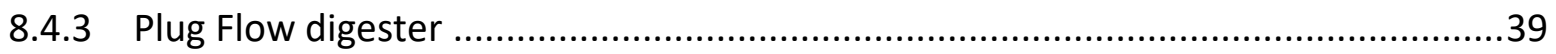

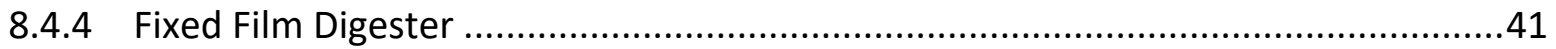

8.4.5 Anaerobic membrane bioreactor .............................................................44

9 Anaerobic digestion technology around the world................................................. 45

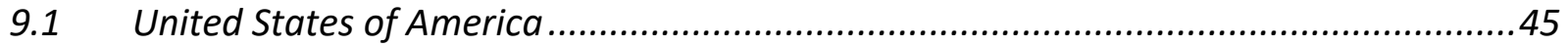

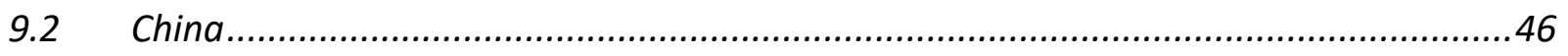

9.3 International prominence of Anaerobic Digestion Technology..............................46

10 Case studies on full scale anaerobic digestion technology across the world................. 49 


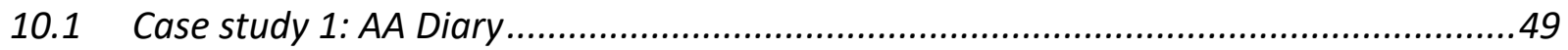

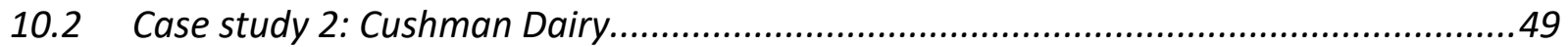

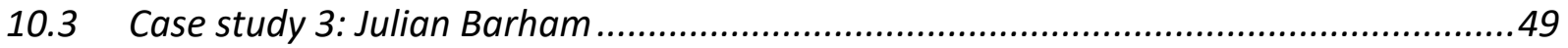

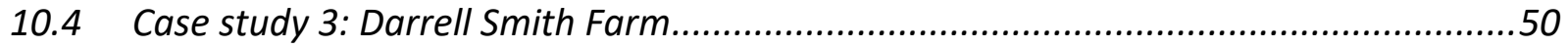

11 Scope of anaerobic digestion technology .......................................................... 50

11.1 Anaerobic digestion technology as a mode of renewable energy ............................50

12 Anaerobic digestion technology in Canada........................................................ 52

12.1.1 Location: Southern Alberta farms..................................................................52

12.2 Canadian anaerobic digestion technology organic processing status:.......................53

12.2.1 Disco Road Plant, Toronto ..................................................................... 53

12.3 The future of anaerobic digestion technology in Canada:....................................55

13 Challenges faced while planning the Anaerobic Digestion technology ........................ 56

14 Advantages of Anaerobic digestion technology............................................... 57

15 Limitations of anaerobic digestion technology. ..................................................... 58

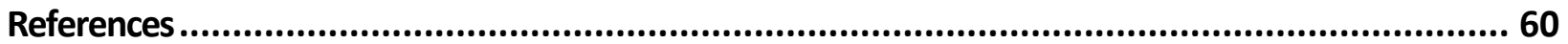




\section{List of Tables}

TABLE 1 TEMPERATURE RANGE OF THE MUNICIPAL ANAEROBIC DIGESTERS FOR METHANE PRODUCTION ................8

TABLE 2 OPTIMUM TEMPERATURE RANGE FOR BACTERIAL GROWTH IN THE DIGESTERS. ..................................8

TABLE 3 COMPARISON BETWEEN THERMOPHILIC AND MESOPHILIC DIGESTERS. .......................................

TABLE 4 DIGESTER TYPES AND THEIR OPTIMUM TEMPERATURE RANGE. ...........................................14

TABLE 5 DESIGN PARAMETERS FOR HIGH RATE ANAEROBIC DIGESTERS................................................28

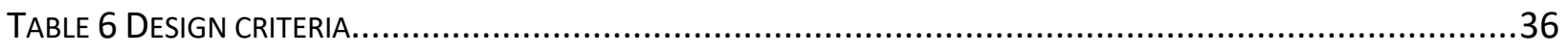

TABLE 7 LIST OF SOME OF THE FIXED FILM ANAEROBIC DIGESTER. .................................................. 42

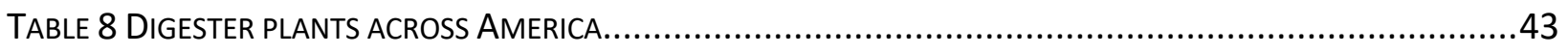

TABLE 9: ANAEROBIC DIGESTER PLANTS ACROSS U.S AND EUROPE...................................................5

TABLE 10 :TOP TEN STATES FOR ELECTRICITY GENERATION BY ADOPTING ANAEROBIC DIGESTION TECHNOLOGY

(MARKET OPPURTINITIES FOR BIOGAS RECOVERY SYSTEMS AT U.S. LIVESTOCK FACILITIES, 2011) ..............52 


\section{List of Figures}

Figure 1 Operational Parameters Depending On temperature ...............................................13

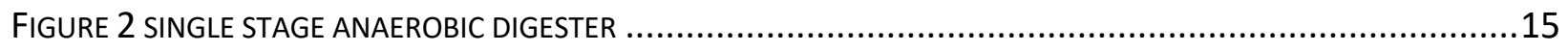

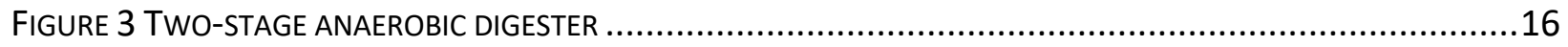

FIGURE 4 CONFIGURATION OF TWO-STAGE DIGESTER................................................................. 17

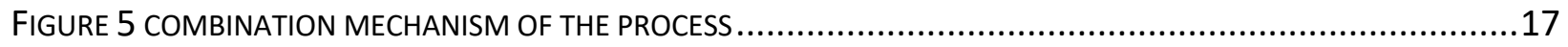

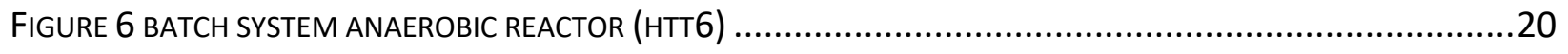

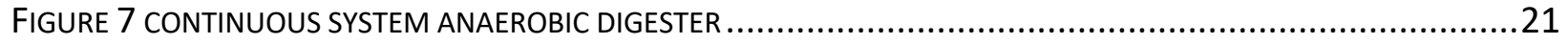

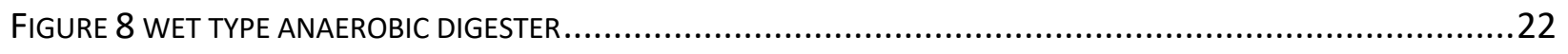

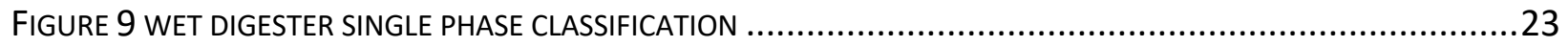

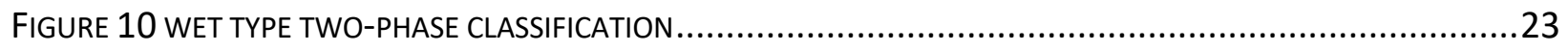

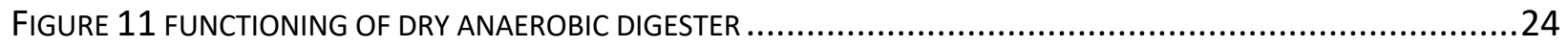

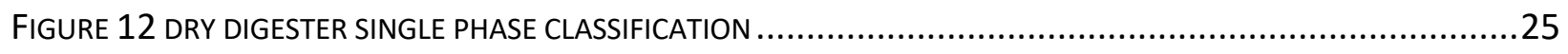

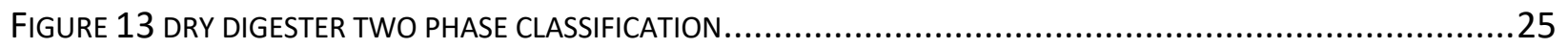

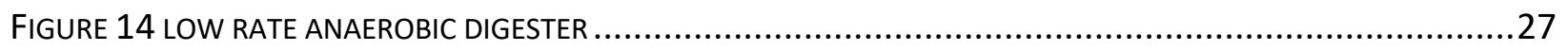

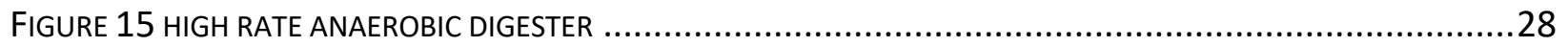

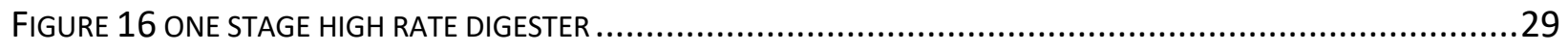

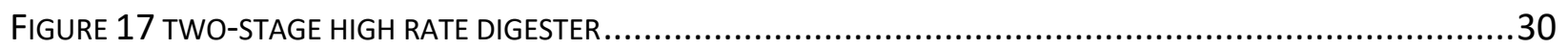

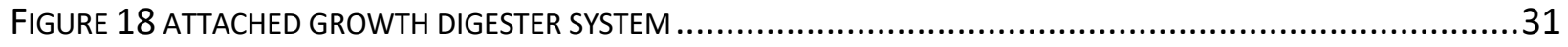

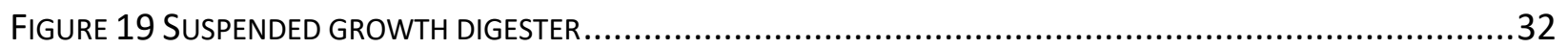

FIGURE 20 PRIMARY AND SECONDARY SLUDGE TREATMENT AT THE MUNICIPAL WASTEWATER TREATMENT PLANT..33

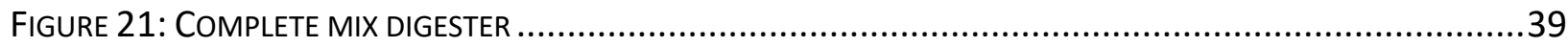

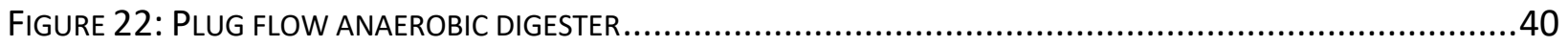

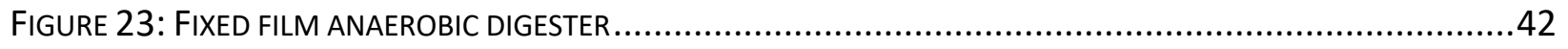




\section{Introduction}

Over the past few years, Anaerobic digestion is considered as one of the dependable modes of treating the disintegrated sludge. With the beginning of treatment by anaerobic digestion technology, it was used only for the treatment of sewage and domestic sludge but over past 20 years, the process of anaerobic digestion has been widely explored. Due to the increase in number of industries and growing population there is a greater production of wastewater and thus, an increase in the demand of sustainable mode of treatment and disposal of the waste water.

Anaerobic digestion technology is a viable method in treating organic wastes and produce renewable energy and also recover nutrients for re-use (like agriculture). The technology is developing as a reliable treatment key for the stabilization and disintegration of sludge. The increase in industries and the population growth are leading in the increase of the amount of wastewater which results in the need for a sustainable method of treatment and disposal.

There are four major steps involved in the degradation which are Hydrolysis, Acidogenesis, Acetogenesis and Methanogenesis. Organic wastes from industry, wastewater treatment plants or households can be treated in biogas plants to produce energy-rich bio-methane.

\section{Hydrolysis}

Hydrolysis is the process of breaking down complex organic compounds/substances into smaller constituent parts and dissolving them into the solutions. Through hydrolysis complex organic substances are broken down into amino acids, sugars and fatty acids.

\section{Acidogenesis}

This process in the further breakdown of remaining organic components after hydrolysis with the help of acidogenic or fermentative bacteria. This process produces VFAs along with carbon dioxide, ammonia and hydrogen sulfide.

\section{Acetogenesis}

This is the third stage of the anaerobic degradation. The molecules produced through the acidogenesis process are further digested with the help of acetogens. Acetic acid, carbon dioxide and hydrogen are produced in this step. 


\section{Methanogenesis}

This is the final stage of anaerobic digestion. In this stage methanogens use the intermediate substances from the previous stages and convert them into methane, water and carbon dioxide. The process of anaerobic digestion technology depends on several factors such as:

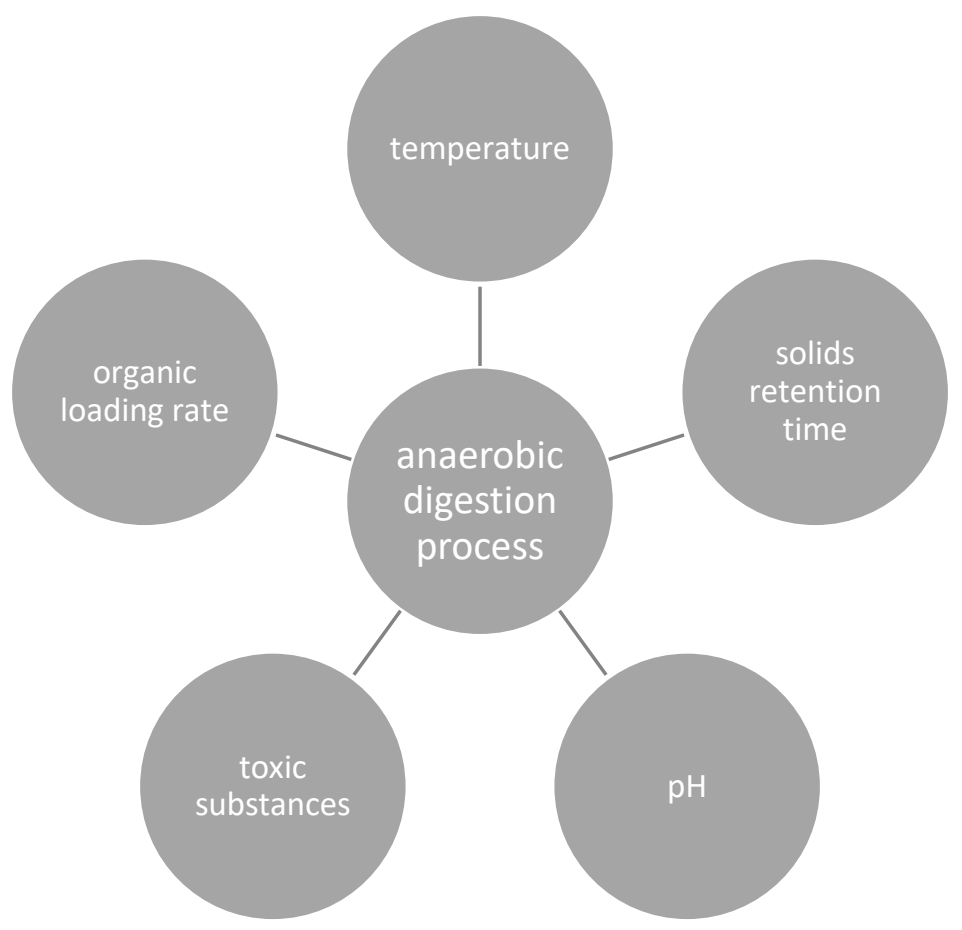

- $\mathrm{pH}$

The mechanism operates under $\mathrm{pH}$ conditions 6.5 to 7.6. Studies show that under low $\mathrm{pH}$ conditions show the association with the possible presence of VFA. The $\mathrm{pH}$ level below 6.3 decreases the methanogenic process and $\mathrm{pH}$ level above 7.8 inhibits bio gas production. Lower $\mathrm{pH}$ level increases the growth of filamentous bacteria and a greater $\mathrm{pH}$ results in collection of ammonia. 


\section{- Temperature}

Anaerobic reactors generally operate at the temperature of 30 to $40^{\circ} \mathrm{C}$ or moderate thermophilic temperature of 50 to $60^{\circ} \mathrm{C}$ in relation with the temperature range of anaerobic microorganisms. 50 to $60^{\circ} \mathrm{C}$ is considered to be more stable and perform well.

- Solids Retention time

Solids retention time is the average time the solids stay in the digester. It is one of the most important parameters as it is related to the growth rate of biomass. Detention time for anaerobic digestion generally ranges from 15 days to 60 days, depending on the mixing capacity in the digester and the temperature.

- Toxic substances

Certain materials cause an inhibitory response, materials with highest concern are metals, ammonia and sulfide. sulfate results in providing an alternate electron acceptor interfering the Production of methane. Presence of Ammonia is one the most important concern as it contains higher concentration of total ammonia nitrogen (TAN). The unionized ammonia is toxic for methanogenic bacteria.

- Organic loading rate

For dilute waste water the loads are generally expressed as biochemical oxygen demand or chemical oxygen demand, for solids or organic sludge's the loads are based on the volatile solids (VS). Methane gas production and the anaerobic process are dependent upon organic loading rates. If the loading increases, the anaerobic process becomes unstable due the more production of volatile acids.

There are various pre- treatment methods to enhance the ability of anaerobic digestion of the sludge and has attracted the attention of various researchers over the decade. Some of the pretreatment methods include,

- Mechanical grinding

- Chemical methods

- Thermal pre-treatment 
- Enzymatic and microbial pre-treatment

For all the processes of anaerobic digestion to be carried out there are specially designed tanks or reactors based on the requirements and type of method used for the treatment which are called as anaerobic digesters.

Anaerobic digesters are the tanks designed to carry out the treatment of soluble waste and insoluble wastewater. The digesters are efficient in treating sewage sludge, agricultural waste and urban wastes. There are thousands of digesters in use around the globe to serve the purpose. The digesters have one base operation to carry out, that is production of methane from the treatment of waste in the digesters. (KHALID, 2011)

There are several types of digesters designed depending up on the type of waste to be treated. For instance, the type of digesters used in treating the municipal wastewater generally come in three types depending upon the temperature - mesophilic, thermophilic and in very few cases psychrophilic anaerobic digesters. For municipal solid waste the type of digesters used are generally single stage or two stage anaerobic digesters. (anaerobic digestion, n.d.)

Most of the anaerobic digesters work on the parameters of temperature range between $30-$ $38^{\circ} \mathrm{C}$, optimum $\mathrm{pH}$ can be $7.0-7.2$, heavy metals are most likely to be eliminated before the addition to the digester tank. (Abedeen, 2010) Anaerobic digesters are designed based on several factors depending on the requirement of the treatment. The important factors depending on which the digesters are designed are,

- Temperature

- Feeding mode

- Biomass

- Solid content

- Number of stages

- Organic loading rate 
Anaerobic digestion technology is mainly used in the production of biogas. Biogas comprises of $60 \%$ methane that can be efficiently used to produce electricity or act as a fuel for the vehicles (cars, buses and trucks etc.) methane is produced from the anaerobic digestion of the waste generated from the sewage and food waste. The anaerobic digestion technology works efficiently with the set of performing inputs and converting them into a resource that be utilized. The input generally comes from manure, industrial waste, wastewater treatment plants and municipal solid waste etc. The waste or the input collected are the feedstock that are then treated with the anaerobic technology with various different digesters depending up on the requirements at the digester plants.

Process Input

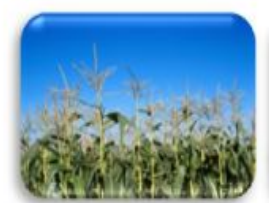

Energy Crops

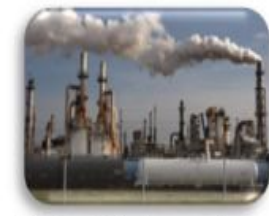

Industrial waste

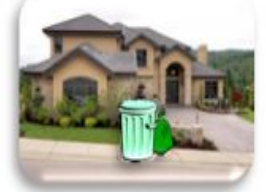

Source separated organics (SSO)/

Municipal Solid Waste (MSW)

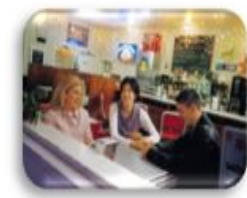

Restaurant/ Food Industry Waste

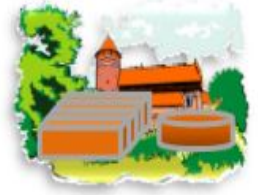

Wastewater Treatment

Plant Sludge
Process Output

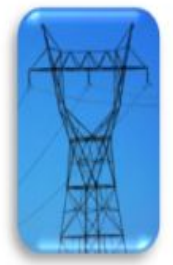

Electricity

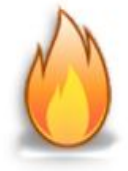

Biogas

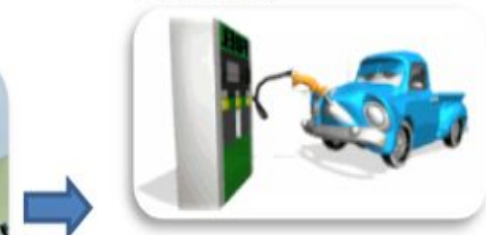

Renewable Fuel

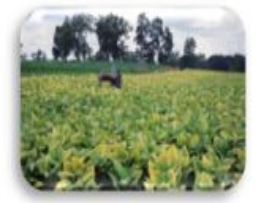

Biofertilizer

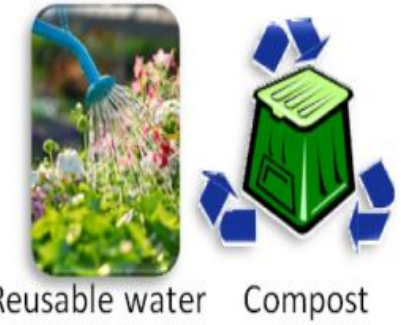

Figure 1: Anaerobic digestion technology (Biogas and anaerobic digestion) 
The most common use of the end product obtained biogas is production of electricity. The usage of non-renewable fuels can be replaced with the use of renewable fuels by using the methane produced from the biogas. It is the best alternate source of energy. Mexico, South America and many countries in Europe have been using the anaerobic digestion technology for the production of methane obtained from the waste. The use of methane produced form the biogas can be the remedy to the energy crisis situation in the present day. Design considerations for the anaerobic digestion plant:

- Must be convenient with respect to the transportation and disposal of waste.

- Heat and energy requirements in the area to the plant location.

- Aesthetic acceptance.

- Capital and operational cost.

- Safety regulations and monitoring etc.

\section{Classification based on temperature}

Anaerobic digesters based on the range of temperature on which the digester can process the anaerobic degradation process can be classified into three main types:

- Mesophilic anaerobic digester

- Thermophilic anaerobic digester

- Psychrophilic anaerobic digester

\subsection{Mesophilic anaerobic digester}

Mesophilic anaerobic digesters are the tanks used for the process of anaerobic digestion with the temperature control from about $30-35^{\circ} \mathrm{C}$. Mesophilic sludge assimilation and methane generation happen at a moderate temperature run. Mesophilic anaerobic processing of slop is usually utilized at metropolitan and modern wastewater treatment process and offers two reasonable and important points of task analogized psychrophilic and thermophilic anaerobic digestion. Initially, there are greater number of anaerobic mesophylls than that of psychrophiles furthermore, thermophiles. Secondly, it is more affordable to keep up mesophilic temperatures 
in digesters than it is to keep up thermophilic temperatures. Most anaerobic digesters in North America work in the mesophilic run.

Methane production can happen over various amount of temperature, but mesophilic digester is the most efficient range in the production of methane especially for treating the municipal wastewater requiring the temperature range of about $35^{\circ} \mathrm{C}$.

When the temperature in the digester is decreased below $32^{\circ} \mathrm{C}$ the production of methane gets slow and a closer check is to be made for the volatile acid and alkalinity ratio. Production of volatile acids continues even at the lower temperature range of about $20^{\circ} \mathrm{C}$ but production in the methane at this temperature is nil. In order to have the greater efficiency it Is important to maintain the digester temperature for at least about $32^{\circ} \mathrm{C}$. (GERARDI, 2003)

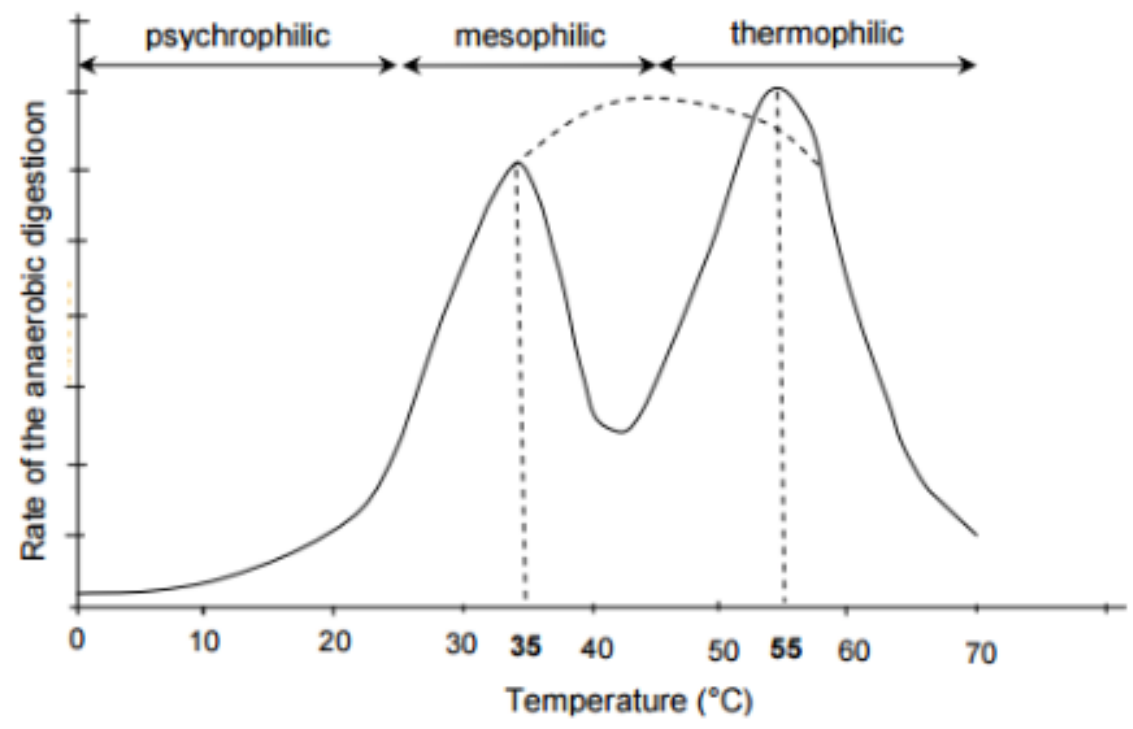

Figure 2 Temperature variation for the digesters

\subsubsection{Advantages of mesophilic anaerobic digesters.}

- Doesn't require very large amount of input energy to carry out the process of digestion of the waste.

- The regulation of temperature within the digester for the operation and functioning is easy and convenient.

- The operational and maintenance cost of the digester is not very expensive and is easily affordable. (Anaerobic digestion.com, n.d.) 


\subsubsection{Disadvantages of mesophilic anaerobic digesters.}

- The mesophilic digester used for the operation if very sensitive and require a keen attention.

- The rate of destruction of the pathogens and other harmful substances is comparatively low.

- The organic loading capacity by the digester for the operation required is low. (Anaerobic digestion.com, n.d.)

Table 1 Temperature range of the municipal anaerobic digesters for methane production

\begin{tabular}{|c|c|}
\hline Digester temperature & Methane production \\
\hline 35 & Optimum \\
\hline $32-34$ & minimum \\
\hline $21-31$ & $\begin{array}{c}\text { Little, the digester getting } \\
\text { sour }\end{array}$ \\
\hline$<21$ & Nil the digester is sour \\
\hline
\end{tabular}

Table 2 Optimum temperature range for bacterial growth in the digesters.

\begin{tabular}{|c|c|}
\hline bacterial groups & Temperature \\
\hline psychrophiles & $5-25$ \\
\hline Mesophylls & $30-35$ \\
\hline thermophiles & $50-60$ \\
\hline hyperthermophiles & $>65$ \\
\hline
\end{tabular}

\subsection{Thermophilic anaerobic digester}

Thermophilic anaerobic digesters are the tanks used for the process of anaerobic digestion with the temperature control from about $50-60^{\circ} \mathrm{C}$. Thermophilic sludge assimilation and methane creation happen at a greater temperature. This type of sludge digestion is more regularly utilized 
at mechanical wastewater treatment plants, where activity warmth or steam is accessible to warm digesters to the thermophilic extend.

When considering the functioning of anaerobic digesters temperature is one of the important aspects for the well operation of the digesters and in the production of methane.

Table 3 Comparison between thermophilic and mesophilic digesters.

\begin{tabular}{|c|c|c|}
\hline Properties & $\begin{array}{c}\text { Thermophilic } \\
\text { digester }\end{array}$ & Mesophilic digester \\
\hline Temperature control & Very difficult & Less difficult \\
\hline Operational cost & Expensive & Not expensive \\
\hline Sensitivity & High & Low \\
\hline Pathogen & High rate & Low rate \\
\hline destruction & & Low \\
\hline Loading capacity & High & \\
\hline
\end{tabular}

On account of the high working temperature of these digesters, sludge processing and the production of methane happen quickly, and noteworthy annihilation of pathogens is accomplished. In any case, notwithstanding high activity costs, thermophilic digesters do have some noteworthy microbiological worries regarding their utilization in debasing sludges. The quantity of thermophilic methane-framing microbes is exceptionally constrained, the bacterial development is moderate, and the bacterial populace encounters a high endogenous demise rate. Additionally, the microbes are exceptionally delicate to variances in digester temperature. Thermophilic digesters are more suitable in the treatment of industrial wastewater. The brief comparison between the mesophilic and thermophilic digesters is mentioned in the table 1.3.1

\subsubsection{Advantages of thermophilic anaerobic digesters:}

- Thermophilic digesters are very efficient in the production of larger amount of biogas.

- The destruction of pathogens and volatile substance is greater in this type of digesters. 
- Based on few researchers it is reported that the hydraulic retention time can be brought down to 3 days at a thermophilic temperature from about 15 to 25 days that is required by the mesophilic digesters considering steady fermentation. (Anaerobic digestion.com, n.d.)

- The hydrogen sulfide content in the sludge is considerably reduced to a greater extent by this type of digesters.

- The volume of the digesters required is considerably small for the process to be carried out.

- The production of foam in the digester is very low or reduced to a greater amount. (Jenicek, 2016)

- The amount of cut down in COD is considerably very fast with respect to reliable loading.

- The separation of solid content from liquid content is much advanced. (Anaerobic Digester upset and troubleshooting, n.d.)

\subsubsection{Disadvantages of thermophilic anaerobic digesters:}

- The heat energy required by the digesters if very high.

- Requires a very good and precise regulation in the variations in temperature.

- The digesters may get damaged due to the high toxic metals if present in the waste to be treated. (Anaerobic digestion.com, n.d.)

- The digesters are very expensive in operation and maintenance.

- Because the metabolism of micro-organisms is high and quick, upsets may occur at a faster rate. (Anaerobic Digester upset and troubleshooting, n.d.)

\subsubsection{Full scale adoption of thermophilic digesters at the Christchurch wastewater treatment} plant.

Adoption of temperature based anaerobic digesters at the Christchurch waste water treatment plant which include thermophilic and mesophilic working in the series.

The configuration of the anaerobic digesters of four mesophilic was replaced by the series thermophilic digesters and mesophilic digesters, there was certainly rise in $67 \%$ in the production of methane gas. In the process about $85 \%$ manufacture in the biogas is from the thermophilic 
digesters. And also accounting the devastation of volatile substances improved by $19 \%$. (shown in the graphical figure below).

The listing of improvement of the digester performance after adopting the series of thermophilic digesters followed by the mesophilic digesters with respective of having only the mesophilic performance; (Bouman, 2008)

Production in the amount of Biogas

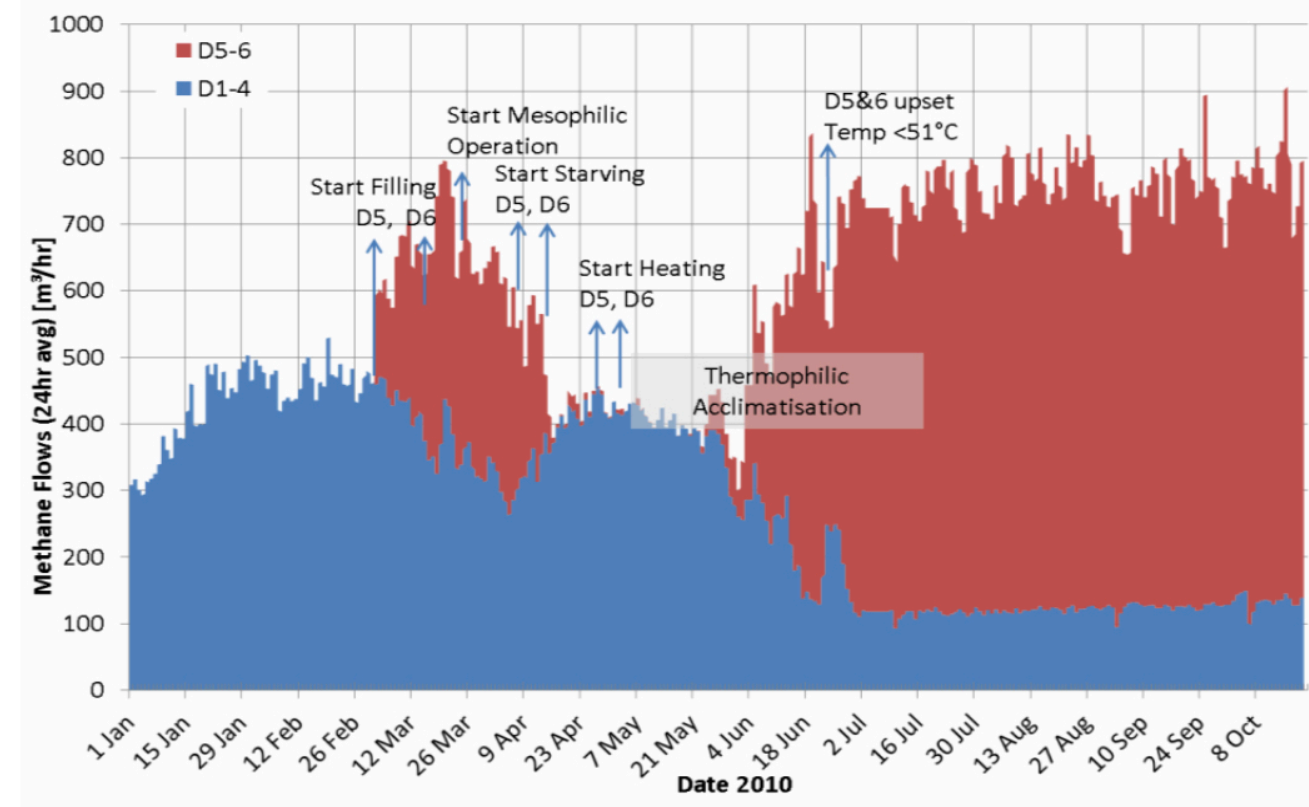

Reduction in the amount of solid content

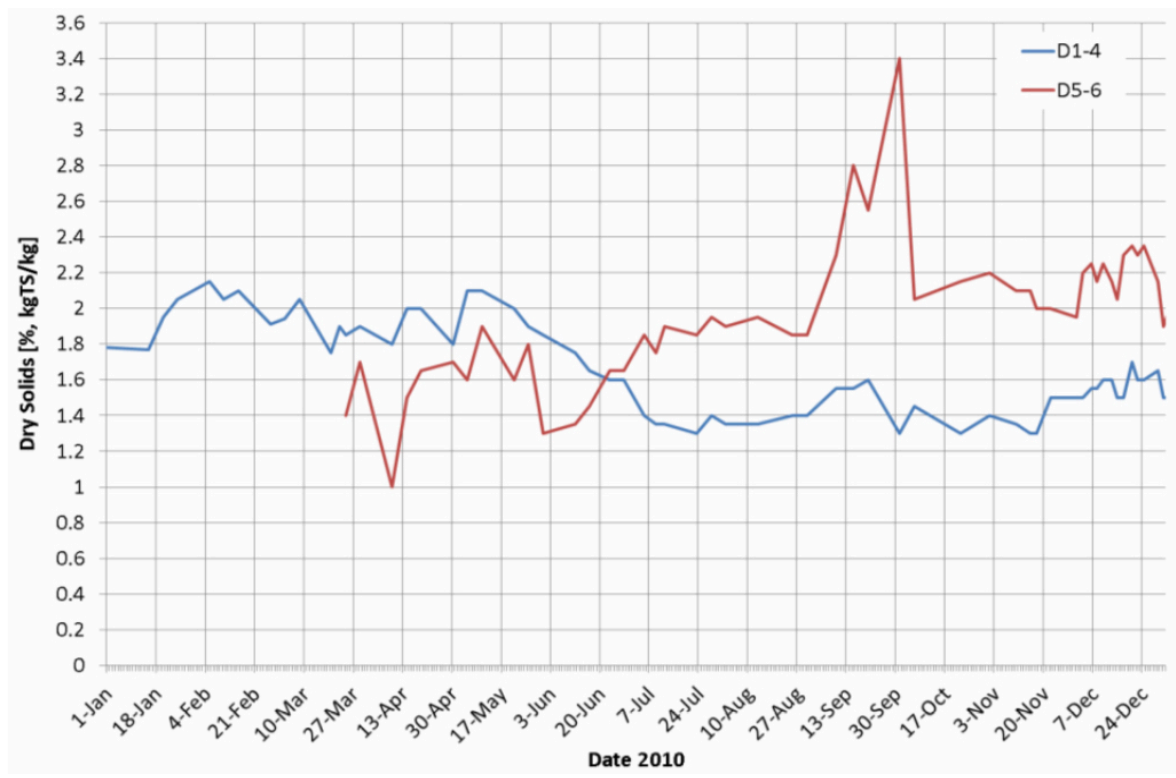




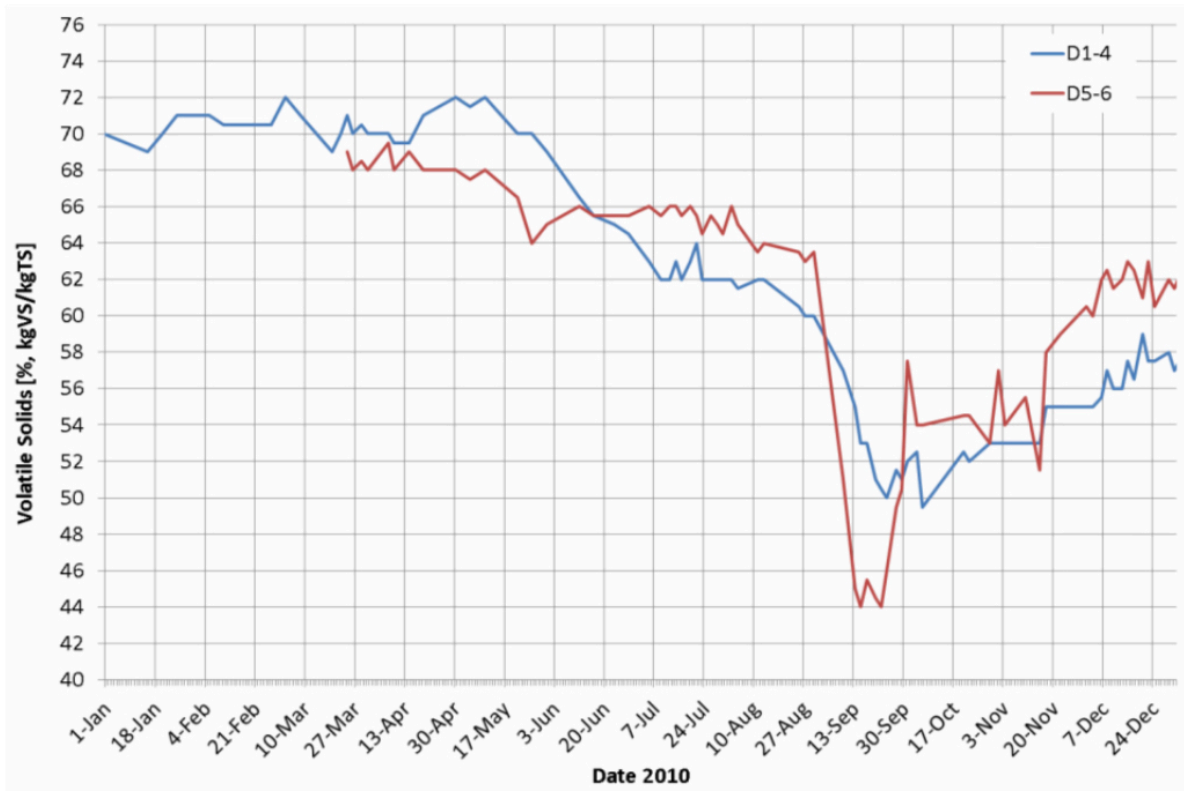

\subsubsection{Case study - Linko Gas, Denmark}

Type of the digester - Thermophilic

Size of the digester $-14,600 \mathrm{~m}^{3}$

Assigned - upgraded in 1999

Capital - DKK 43.6 million

The project comprises of about 50 workers, having the main focus to reduce the problems of odor being experienced by the people and also to fulfill the requirements laid out by the government.

The plant initially had a digester working on mesophilic condition installed in the year 1990, bearing the load of about 354 tonnes every day. With the rise in the capacity of the feedstock and the demand for a new technology the plant reinstalled or upgraded the existing digester with the thermophilic anaerobic digester which resulted in obtaining the double of manufacture in biogas. The plant at the Lintrup thus became the one of the largest for its kind in the whole world. The plant handles of an average 280,000 tonnes of compost and waste per year. (Pullen, 2015) 


\subsection{Psychrophilic anaerobic digester}

Psychrophilic anaerobic digesters are the tanks used for the process of anaerobic digestion with the temperature control from about $5-20^{\circ} \mathrm{C}$. Psychrophilic sludge assimilation and methane generation happen at a moderately low temperature extend. As a result of not exactly ideal movement of the anaerobic microscopic organisms in the psychrophilic temperature go, absorption of slime is constrained to little scale activities, for example, Imhoff tanks, septic tanks, and slime tidal ponds. The temperature of the digester substance is roughly the temperature of its encompassing condition and shifts from season to season. Since temperatures in psychrophilic digesters are moderately low, the SRTs of these digesters are more prominent than hundred days. (GERARDI, 2003)
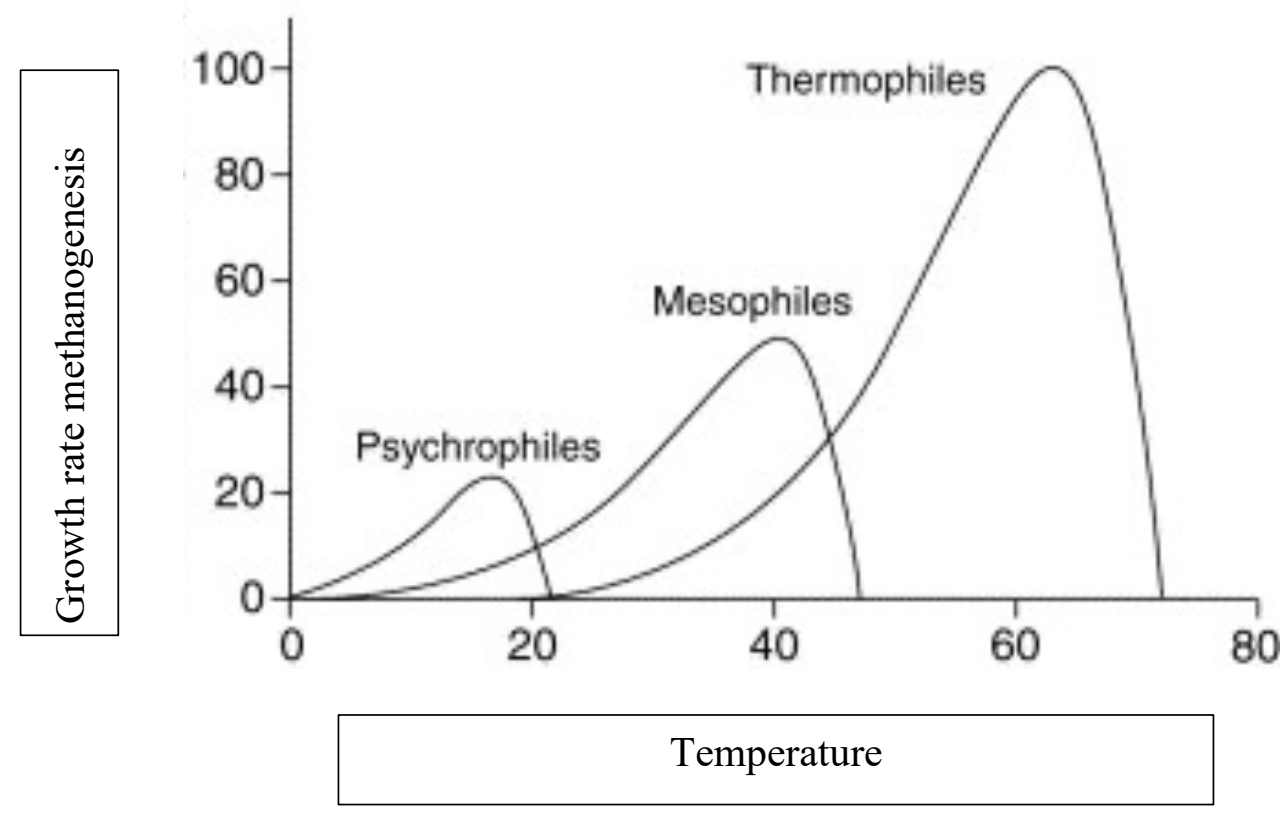

Figure 3 Operational Parameters Depending on temperature

Mesophilic anaerobic digesters and thermophilic anaerobic digesters are the most common types that have been in practice for a period of time, but a study by (L. Przywara) shows us how the psychrophilic conditions work efficiently in treating the municipal sewage. The research followed a condition of hydraulic retention time of 30 hours, load applied of $0.051 \mathrm{~m}^{3} / \mathrm{m}^{2} \mathrm{~h}$. The research gives a clear explanation of how the psychrophilic digesters can efficiently be used for the treatment of wastewater. 
Table 4 Digester types and their optimum temperature range.

\begin{tabular}{|c|c|c|}
\hline Type & temperature & $\begin{array}{c}\text { Solid retention } \\
\text { time(days) }\end{array}$ \\
\hline Psychrophilic & $5-20^{0} \mathrm{C}$ & $60+$ \\
\hline Mesophilic & $30-35^{0} \mathrm{C}$ & $25-30$ \\
\hline Thermophilic & $50-50^{0} \mathrm{C}$ & $5-12$ \\
\hline
\end{tabular}

\subsubsection{Advantages of psychrophilic anaerobic digesters.}

- The level of stability is very high and efficient.

- Easy in operation hence can work without a professional attention.

\subsubsection{Disadvantages of psychrophilic anaerobic digesters.}

- Organic loading rate is very low.

- Special care is required for the walls of the digesters.

- Not very much in practise.

\section{Classification based on number of stages}

This type of classification is based on the number of stages/ series through which anaerobic digestion takes places in the digester. Generally, there are two main types based on the stages:

- Single stage anaerobic digester

- Two-stage anaerobic digester

\subsection{Single stage anaerobic digester}

A characteristic single-stage digester is generally designed with a single tank for the whole process of the anaerobic digestion. Digester processes involve the addition of sludge and extract, mixing, warming and air gathering all in one tank. All the actions are likely due to stratification of reactor substance. Stratification grades the subsequent films from upper to lowermost of the tank: gas, scum, supernatant, sludge, and grit (figure 3). (GERARDI, 2003) 
Single stage reactors tend to effortlessly upset than two-stage reactors. This happens due to the occurrence of concurrent processes of two different collections of the bacteria's, the bacteria's resulting the production of acids and the bacteria's resulting the formation of methane. The growth of the bacteria's resulting in the formation of acid is quicker when compared to the bacteria's resulting in the formation of methane and also, they are much accepting to the changes in operation circumstances which may lead to the unevenness between the amount of production of acid and methane. The unevenness might lead in the reduction in $\mathrm{pH}$ and alkalinity resulting in the failure of the reactor.

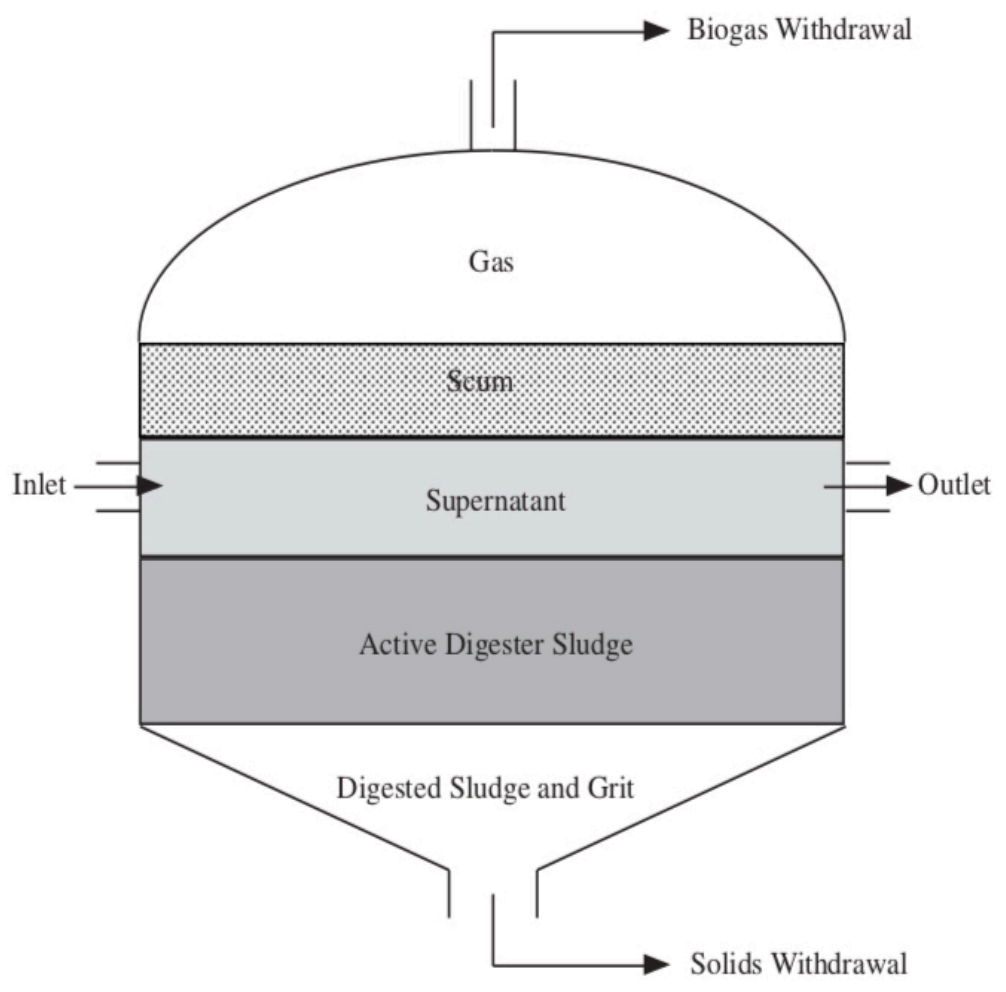

Figure 4 single stage anaerobic digester

\subsubsection{Advantages of single stage anaerobic digester}

- The single stage anaerobic digesters are simple in construction and operation.

- This type of digesters is cost effective and economical.

- The designing of the digesters is very flexible. 


\subsubsection{Disadvantages of single stage anaerobic digester}

- The chances of failure in single stage digesters is noticed more commonly.

- When compared to two stage reactors, the single stage digester is very less effective in the functioning.

- $\quad$ This type of digesters cannot take up as much load as two-stage digesters.

\subsection{Two-stage anaerobic digester}

Two-stage reactor arrangements have minimum of two different tanks for the digestion process. In this type of arrangement, the efficiency and strength of the reactors are much advanced and improved when compared to that of single stage system. This type of mechanism is efficient in producing methane and reduction in the solid content very much similar to the single-stage system. The removal of toxicants is done in the earlier step. In some types of two-stage digesters the production of acids takes place in the initial step or reactor and methane in the second step;

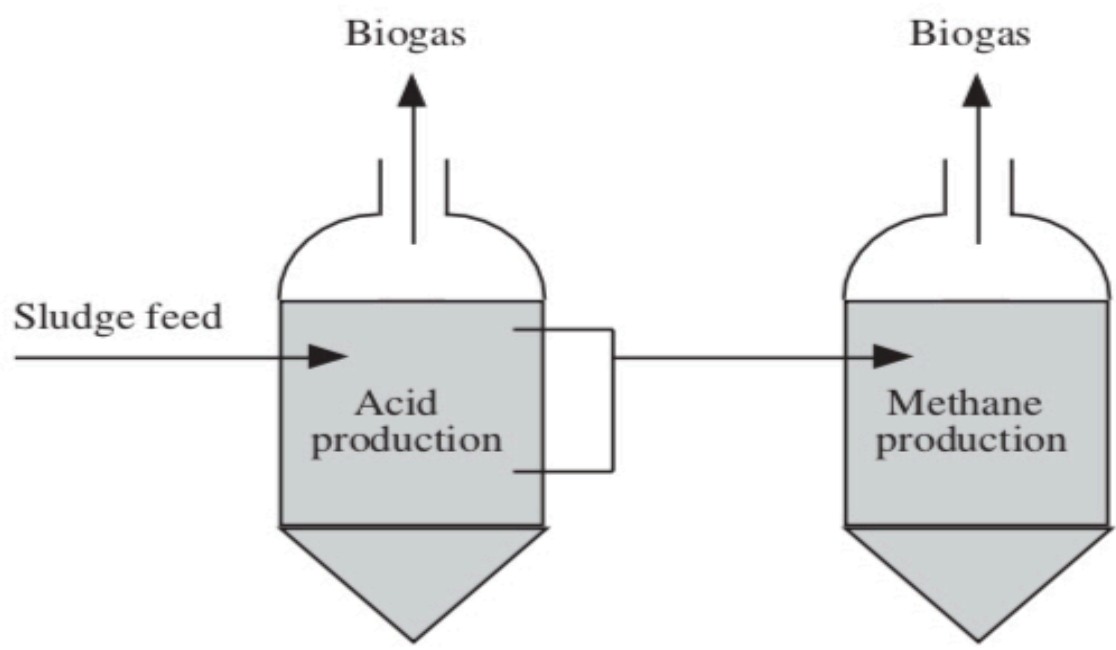

Figure 5 Two-stage anaerobic digester

Whereas in few other types, the production of methane and the sludge digestion happen concurrently in the one reactor and the thickening of sludge in the second reactor (figure 5). (GERARDI, 2003) 


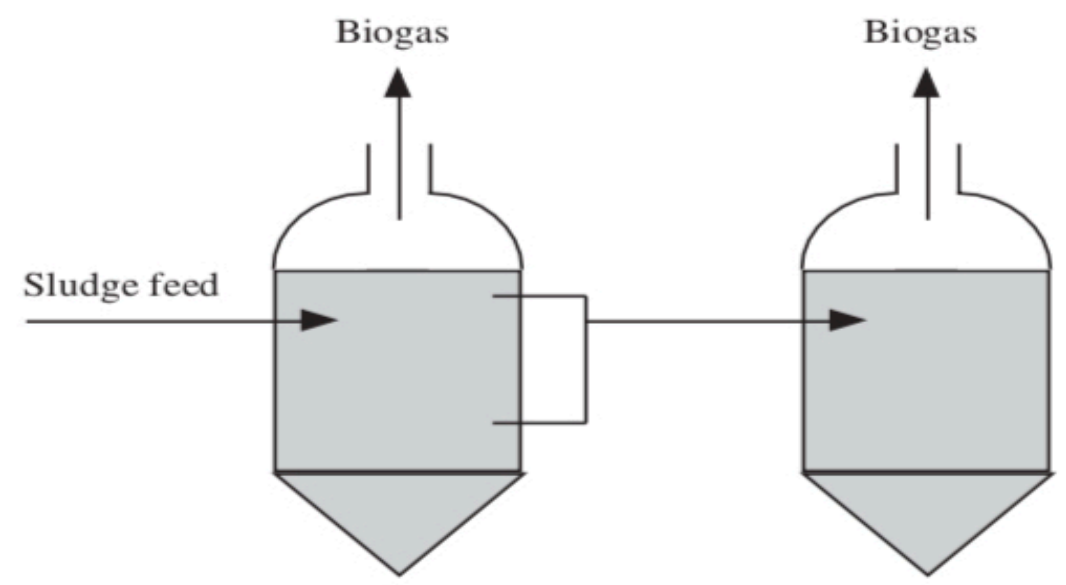

First stage

Second stage

Sludge digestion and methane production

Thickening and dewatering

Figure 6 Configuration of two-stage digester

The continues mixing and heating for sludge digestion happens in the first stage, in the second stage stratification is allowed where storage and thickening occurs. Further another type of two stage process comprise of temperature dependent method of sludges. These mechanisms work in both the combination of mesophilic and thermophilic temperatures (figure 6). These arrangements aid in the better dewaterability of sludges and decrease in the number of pathogens.

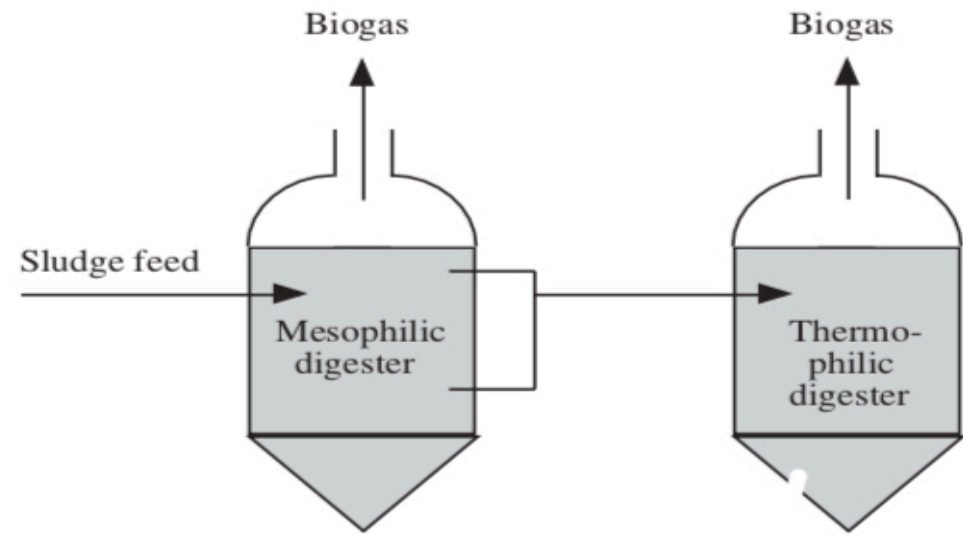

Figure 7 Combination mechanism of the process 


\subsubsection{Advantages of two-stage anaerobic system:}

- Two-stage system digesters are very flexible in designing.

- Two-stage system digesters can be more reliable.

- The heavy metal compost in this system is very low.

- This type of system has better biological stability when compared to the other types. (P. Vandevivere, 2002)

- There is greater enhancement in the manufacture of biogas.

- Improved control regarding the odor aspect. (Staged Anaerobic Digestion, n.d.)

\subsubsection{Disadvantages of two-stage anaerobic system:}

- This type of system is very complex

- The initial investment in this type of digesters is very large.

- The biogas production is less when the solids are not methanogenic.

- This type of system requires a large amount of initial investment. (P. Vandevivere, 2002)

\section{Classification based on feeding mode}

Feeding mode is the action by which the feedstock is put into the digester for the anaerobic digestion to take place and produce the necessary outputs, there are two main types based on this type:

- Batch system anaerobic digesters

- Continuous system anaerobic digester

\subsection{Batch system anaerobic digester}

In the batch system the reactor is been filled with the slurry which is made to stay in the tank till the required treatment time. Once the treatment is done, the treated biodegradable slurry is taken out and new batch of supplies are added.

This kind of digesters have benefits where the convenience of raw supplies is periodic or inadequate to course materials requiring treatment with an apparatus which might be required to arranged at a given or certain time. Batch system reactors need a bit of everyday 
attention. Though, the production in the amount of gas is irregular, as there is rise gradually after the start and falls slowly with a period of greater generation. Batch system are very efficient and inexpensive and also the assessment of the amount of digestion is much simpler.

The drawback in the creation of irregular gas can be decreased with the extra usage of one more batch digester which is charged at regular breaks. Because of their low gas production ability, the batch mechanism might need the expenditure of an extra reactor that will be restricted to minor farms. There is a greater fluctuation in the manufacture of the gas and the quality of the production.

Batch type reactors have greater expiration of solids with pre-screening, 1-2 stages and around ten acres of land for the mechanism that can take up to 40000 tons every year. (PULLEN, 2015)

\subsubsection{Advantages of batch system anaerobic digester.}

- Simple in the operation.

- Level of designing work is minimum.

- Cost efficient.

- Easy maintenance

\subsubsection{Disadvantages of batch system anaerobic digester}

- Odor problems is the main concern.

- Channeling may occur within the digester.

- Clogging in the digester can also cause a concern. (Chunlan Mao, 2015) 


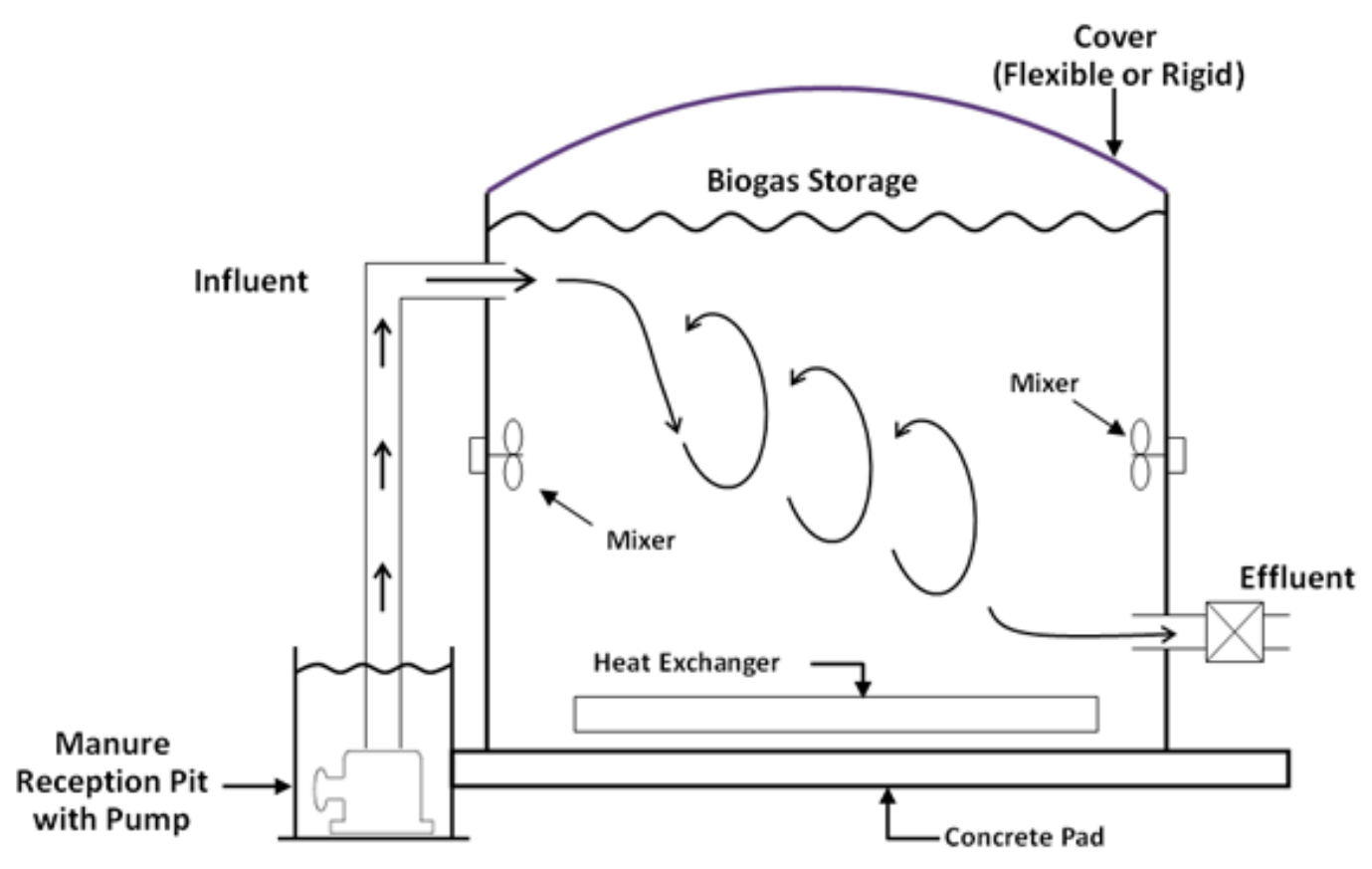

Figure 8 Batch system anaerobic reactor (htt6)

\subsection{Continuous system anaerobic digester}

In the continuous feed system, certain amount of slurry is fed to the reactors at given intervals of time with the discharge of the existing materials from the reactors every time new feedstock is added to the tanks. In this type of mechanism, the amount of sludge and gas produced is even. This kind of mechanism is well suited where the availability of raw feedstock is consistent with the good amount of source.

In this type of system, a little quantity of the new raw material might overflow without being digested. But with the good rate of mixing the wastage can be insignificant. Incorporating baffles or any other parameters would be considered in order to prevent the overflow of the raw materials. 


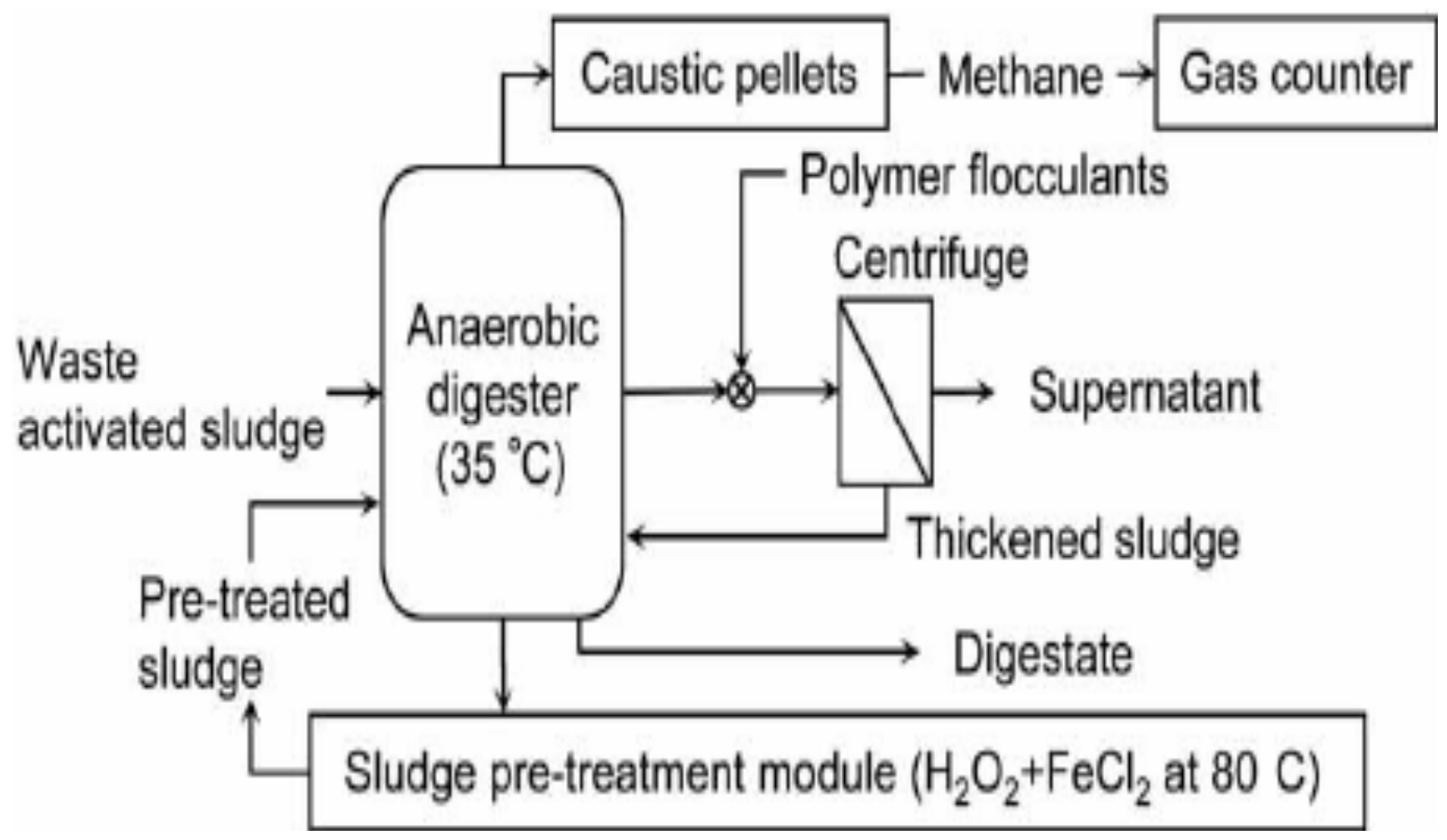

Figure 9 continuous system anaerobic digester

Continuous stirred tank digesters expanded granular sludge beds, up-flow anaerobic sludge blankets are few of the example for continuous system anaerobic digesters.

\subsubsection{Advantages of continuous system anaerobic digester}

- The operation cost is very low hence more economical.

- Most commonly type of used digester due to convenient mode of operation.

- The mode of digestion is rapid due to constant environmental surroundings.

\subsubsection{Disadvantages of continuous system anaerobic digester}

- As there is continuous supply of the feedstock constant mixing is required.

- Lot of aeration is required in the tank as there is regular supply of the feedstock.

- The energy required for the processing is comparatively high. (Abedeen, 2010) 


\section{Classification based on solid content}

Depending on the number of total solids present in the substrate there is a classification among which are:

- Wet type anaerobic digester

- Dry type anaerobic digester

\subsection{Wet type anaerobic digester}

Wet digesters also known as low solids anaerobic digester technique usually routes the raw materials lesser than 15 percent solid content. The raw materials available for this kind of reactors are generally in slurry practice which are easy to pump.

Before the feedstock is added into the digester tank it is very well conditioned to meet the required dry matter substance with the addition of process water. Wet-single pass digesters are commonly used in this type of mechanism. The most suitable type of mixing for wet digesters can be mechanical stirring or by installing hydraulic stirring. (Chaoran, 2015)

- single digester reactor mechanism comprises about two to 3 acres of land with greater dependency on the availability of feedstock. (PULLEN, 2015)

- Two stage digester mechanism comprises about five to six acres of land with the dependency on the availability of feedstock.

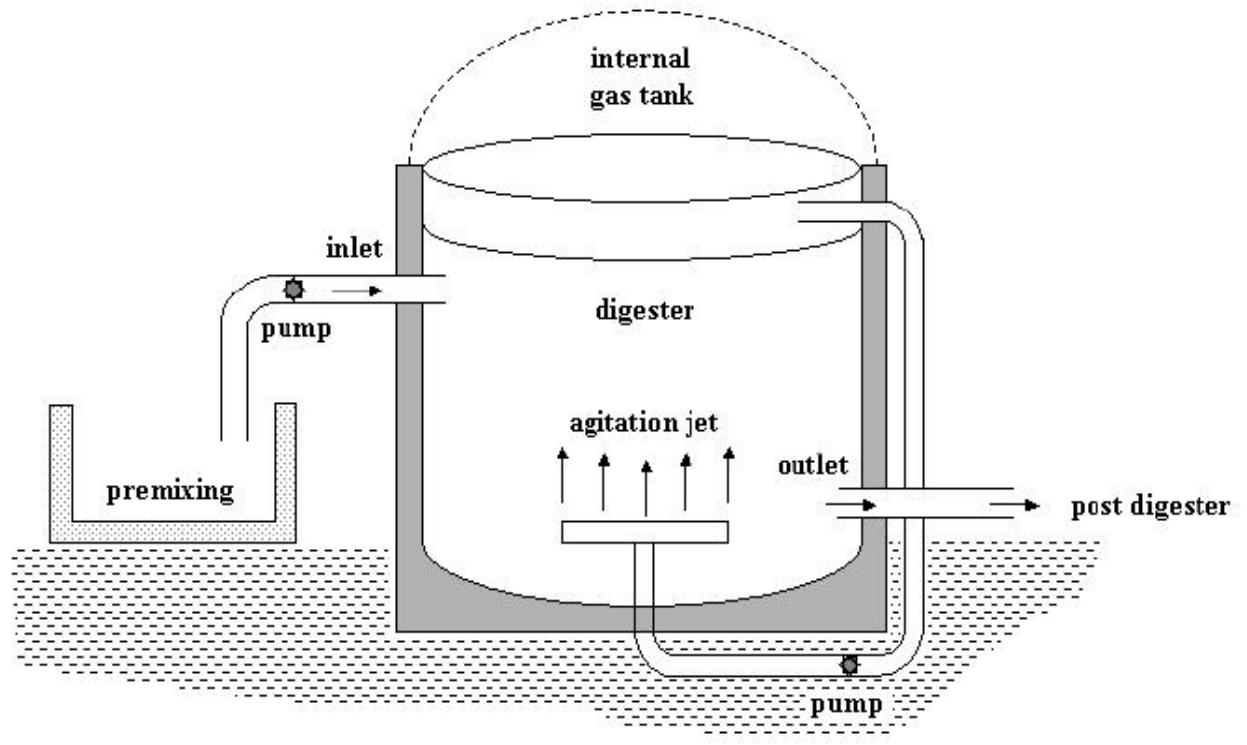

Figure 10 wet type anaerobic digester 


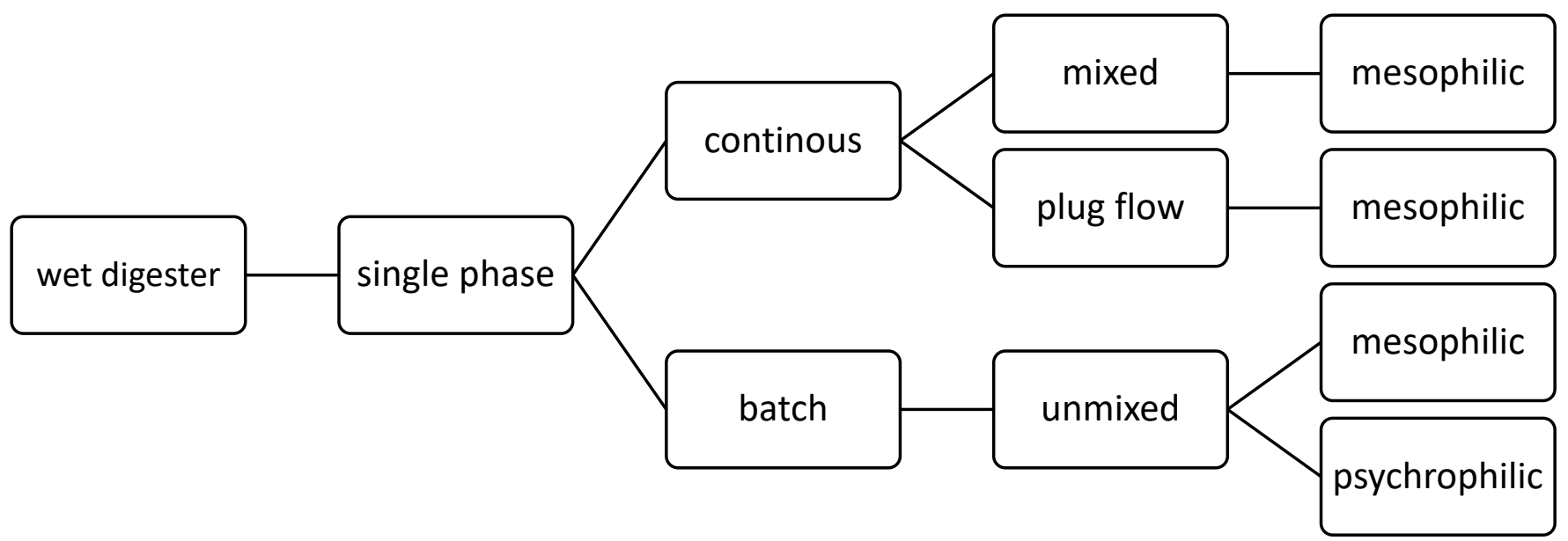

Figure 11 wet digester single phase classification

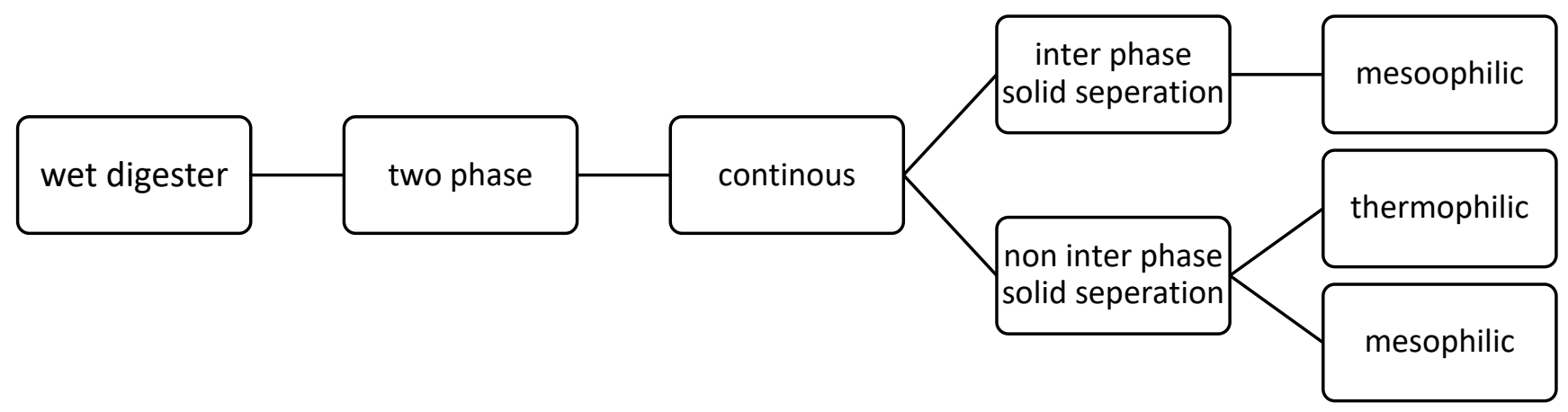

Figure 12 Wet type two-phase classification

This type of anaerobic digestion requires more amount of pre-treatment when compared to dry anaerobic process. And also accounting to requirement of cost efficiency and energy input can be greater than required by the dry anaerobic digestion. 


\subsection{Dry type anaerobic digester}

Dry digesters also known as high solids anaerobic digesters technique usually routes the raw materials greater than 15 percent solids content. The raw materials for this mechanism are designated as stackable. Usually the feedstock added in the digester tank is supposed to have about $25-40 \%$ of dry matter. The complete mixing process is not very suitable type of stirring that can be adopted in dry digesters. Dry type digesters are more effective due to the following reasons,

- The energy requirement for the mechanism is very less.

- Very less or no process water addition is required.

- The loss in nutrient level is generally very low.

- This type of digester is more effective as the pre-treatment required is very less.

- The organic loading rate in this type of digesters is considerably very high.

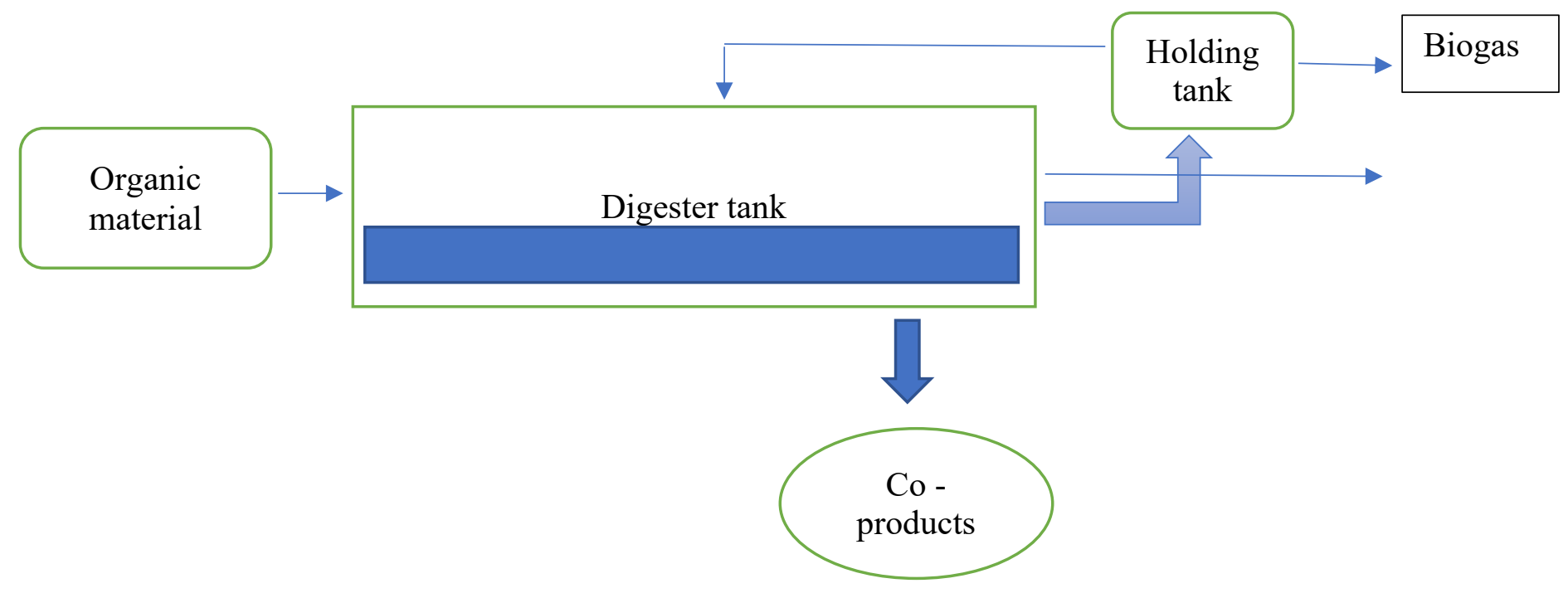

Figure 13 Functioning of dry anaerobic digester 


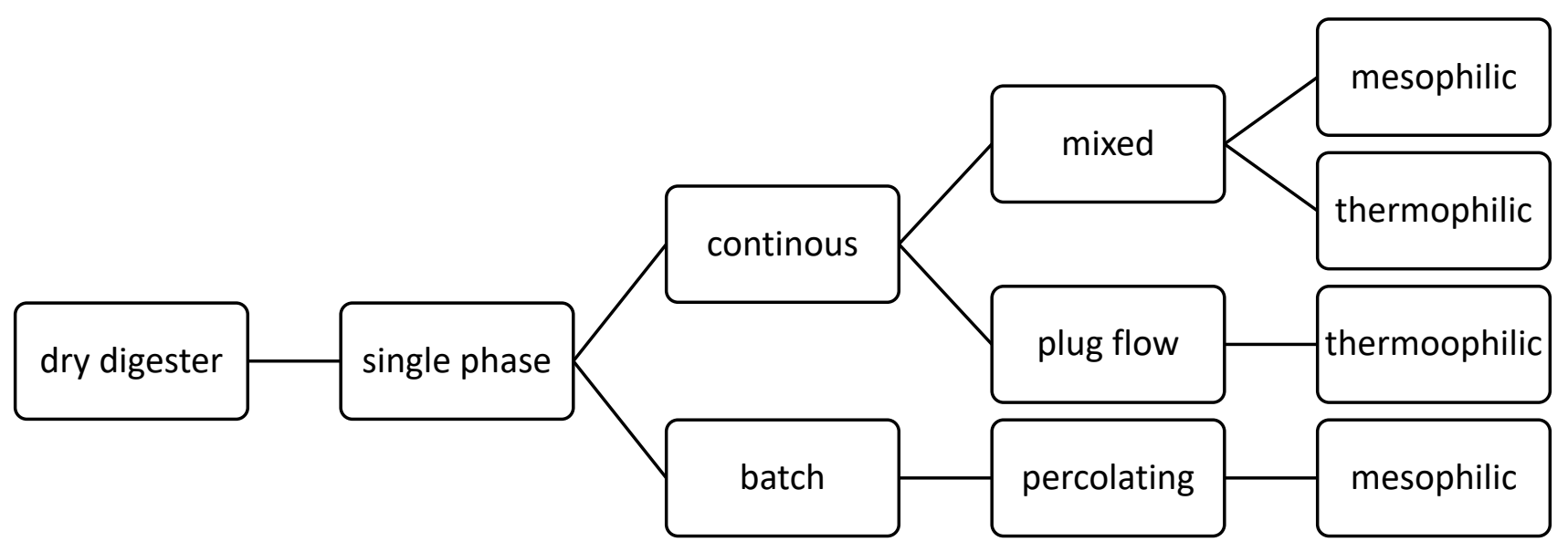

Figure 14 Dry digester single phase classification

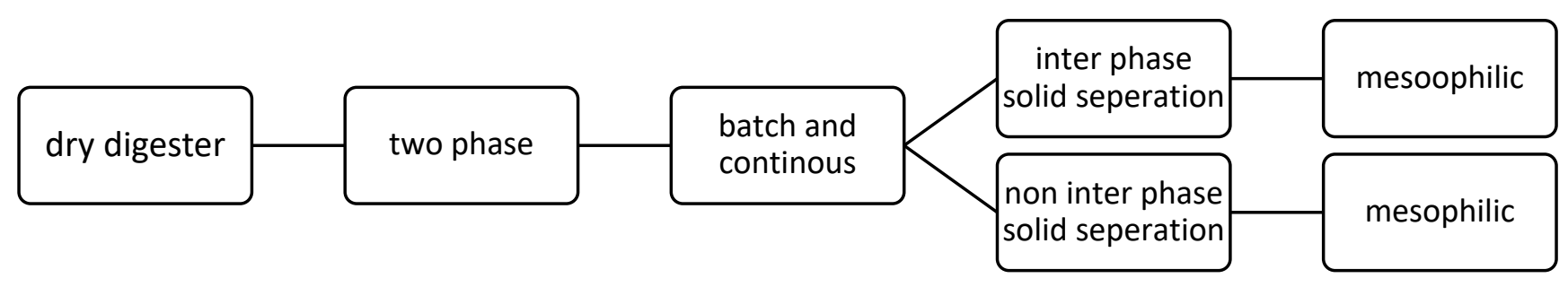

Figure 15 Dry digester two phase classification 


\subsubsection{Advantages of dry anaerobic digester}

- Very economical to use.

- This type of digesters is very simple and not very complex.

- Very low maintenance required for the digesters.

- The equipment's installation is very simple and not too difficult materials required in the assembly and operation.

- Very economical operational costs.

- The most tolerant system for the pollutants.

\subsubsection{Disadvantages of dry anaerobic digesters}

- Special equipment's are required for the process of loading and unloading to be carried out.

- Sometimes the output yield is low but not necessarily all the time.

- It is not completely mixed.

- $\quad$ Digester space is more comparatively. (R. Waltenberger, 2013)

\section{Classification based on organic loading rate}

Organic loading rate is the amount by which the feedstock is loaded to the digester, there are two types of digesters depending up on the loading rate:

- Low rate anaerobic digester

- High rate anaerobic digester

\subsection{Low rate anaerobic digester}

Low rate reactors are made up of one tank without any mixing instrument designed in the tank. The process of sludge thickening and digestion takes place together in this type of reactors. In this type of system, the biogas is emitted on the addition of the sludge for active digestion. The settleable-particles from the flotation settle down at the bottom of the tank resulting in the formation of a layer called as scum layer. There is formation of 4 different zones in the tank due to the process of digestion (figure 15). The different zones formed are namely active sludge and stabilized zone, scum zone and supernatant zone. 


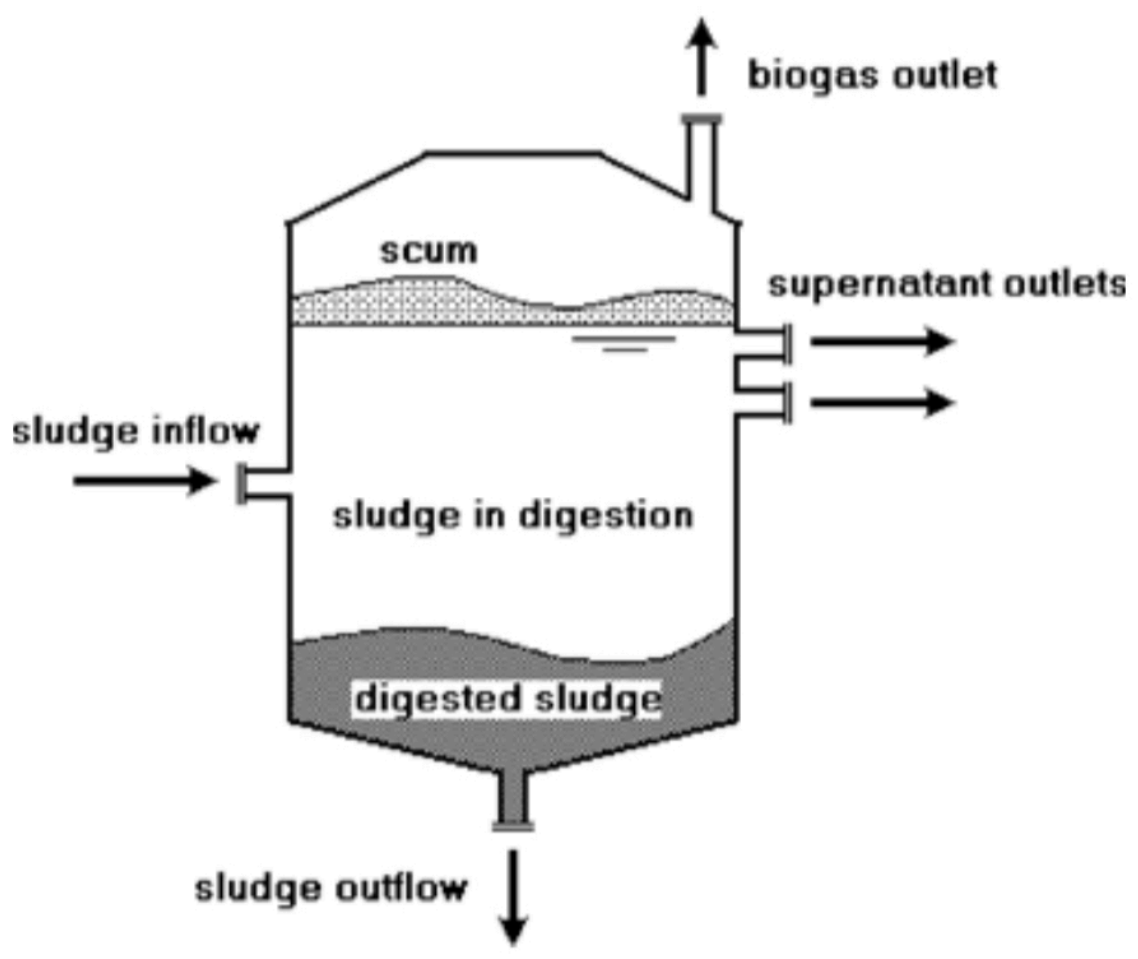

Figure 16 Low rate anaerobic digester

This type of digesters is used in the small treatment plants where the high loading rate is not required, and the treatment capacity is less. Low rate anaerobic digesters have low handling and disposal cost making them economical and affordable. As this type of digesters are very simple, they require less material demand and maintenance. Not very greater attention is required for the smooth working or operation of the digesters.

\subsection{High rate anaerobic digester}

High rate digesters have large capacity of loading rates some with single stage and some with two stage of separation. The mixing and hydraulic conditions in this system are simpler and easier to control. This system is highly efficient in treating wastewater with greater concentrations of organic materials. The wastewater surcharges are eliminated in this kind of system. The loading 
amount and the operational functions are maintained through external circulation conditions. The designing in this system can have either one stage or two stage digesters.

(CHERNICHARO, 2007)

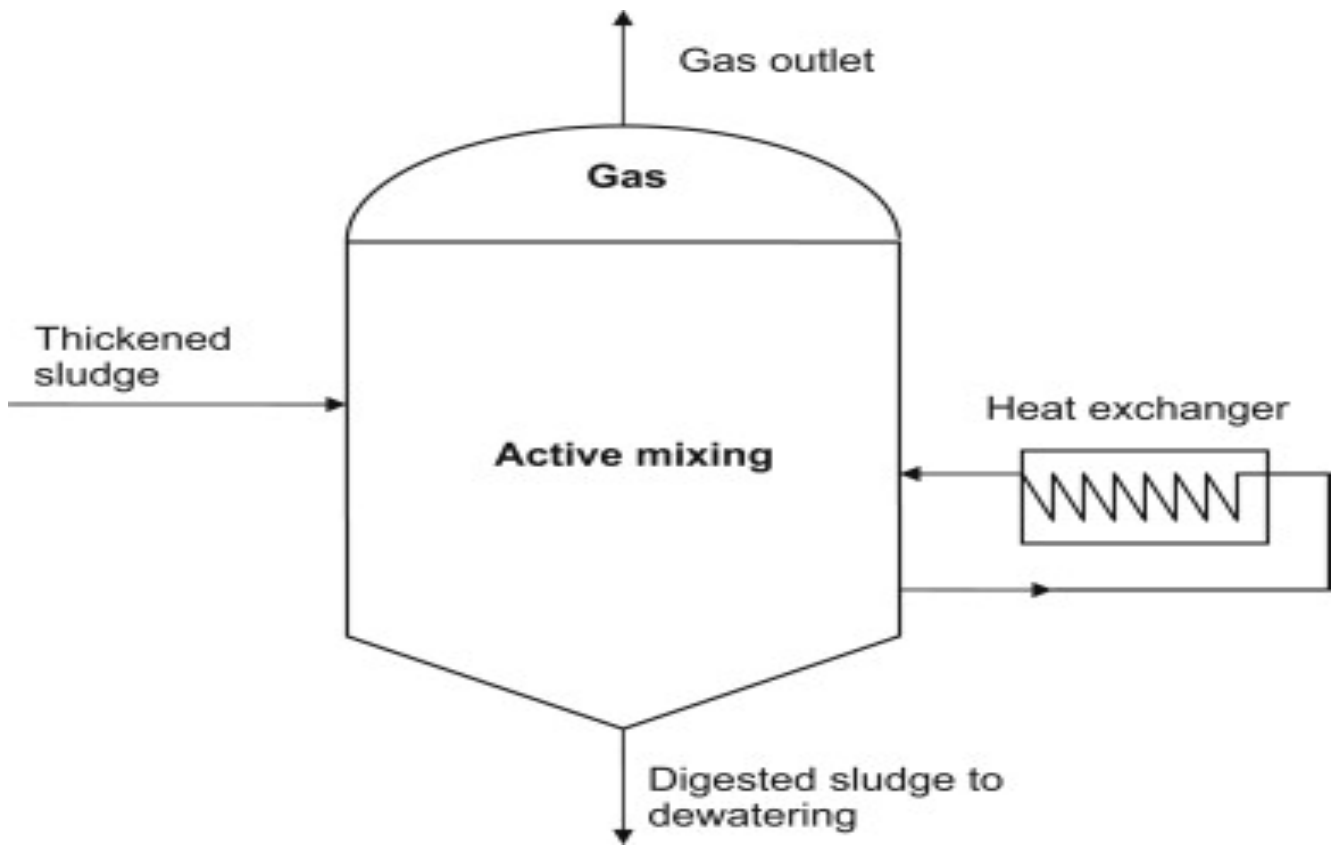

Figure 17 High rate anaerobic digester

Based on a study it was found that the design criteria for the high rate anaerobic digesters depending up on the hydraulic time (HRT), hydraulic loading rate (HLR), and organic loading rate (OLR) as mentioned below in the table 5. (Arita, 2013)

Table 5 Design parameters for high rate anaerobic digesters

\begin{tabular}{|c|c|c|c|}
\hline $\begin{array}{c}\text { High rate anaerobic } \\
\text { reactor }\end{array}$ & HRT (Hours) & HLR $\left(\mathrm{m}^{3} / \mathrm{m}^{2}-\mathrm{hr}\right)$ & OLR $\left(\mathrm{kg} / \mathrm{m}^{3}-\mathrm{d}\right)$ \\
\hline $\begin{array}{c}\text { Up flow anaerobic } \\
\text { sludge blanket } \\
\text { (UASB) }\end{array}$ & 6 & $0.7-1.5$ & $15-30$ \\
\hline $\begin{array}{c}\text { Up flow anaerobic bed } \\
\text { tank }\end{array}$ & $\begin{array}{c}0.9-3 \text { (different } \\
\text { industrial waste) }\end{array}$ & 2 & $10-20$ \\
\hline Hybrid & 12 & $20-24$ & $1-6$ \\
\hline
\end{tabular}




\subsubsection{One stage high rate anaerobic digester}

One phase high rate digester includes additional fraternisation and heating process, furthermore the process is functioned with the even serving rates. In this type of system, the tank size is usually decreased in volume and stability is increased (figure 17) represents the simple configuration of the system). Below the figure represents the relation between the temperature and the retention time required for design of the digester. The solid retention time corresponds to the hydraulic detention time as this process does not have the property of the solid retention time.

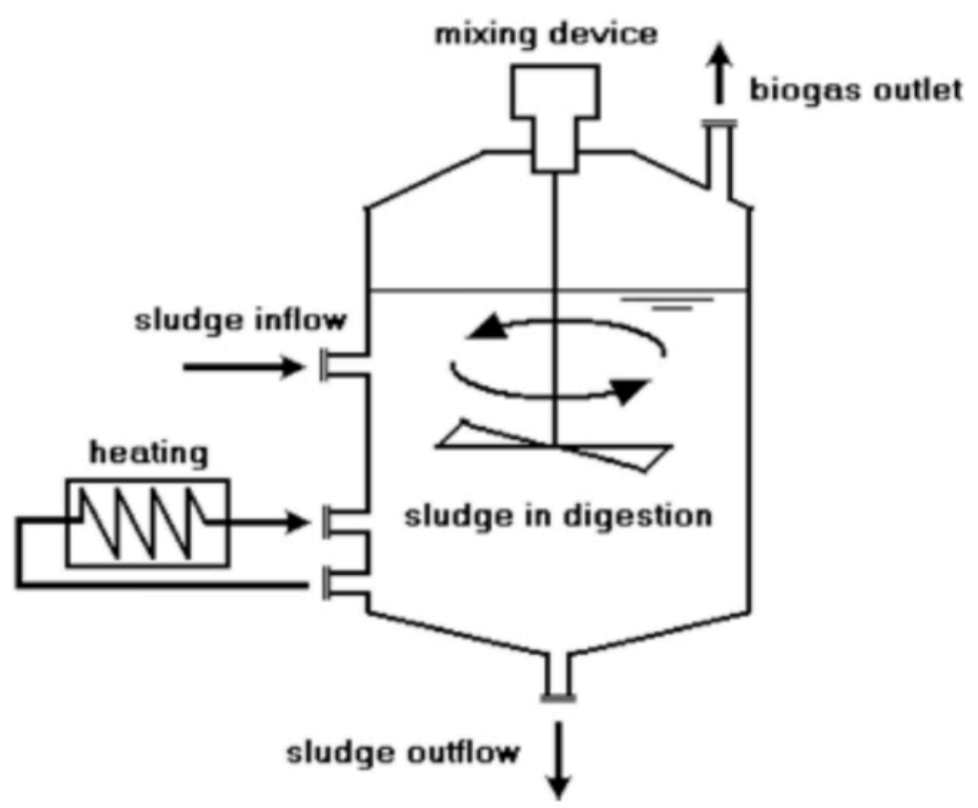

Figure 18 One stage high rate digester 


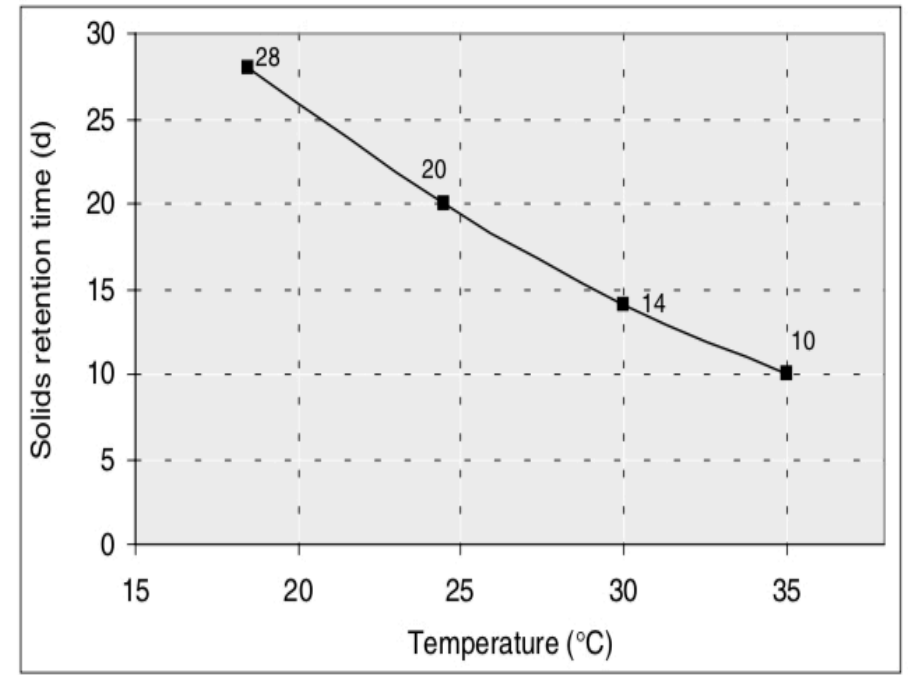

\subsubsection{Two stage high rate anaerobic digester}

Two stage high reactor is the digester with the addition of the second tank with the operation of the high rate simple digester (figure 17) is the simple illustration of two stage high rate reactor. In this type of system, the first or primary tank functions in the sludge digestion accompanied with the mixing and heating instruments for the operation. the following digester or the second digester available is used for the storage and the sludge digested in the primary process resulting in the availability of elucidated supernatant.

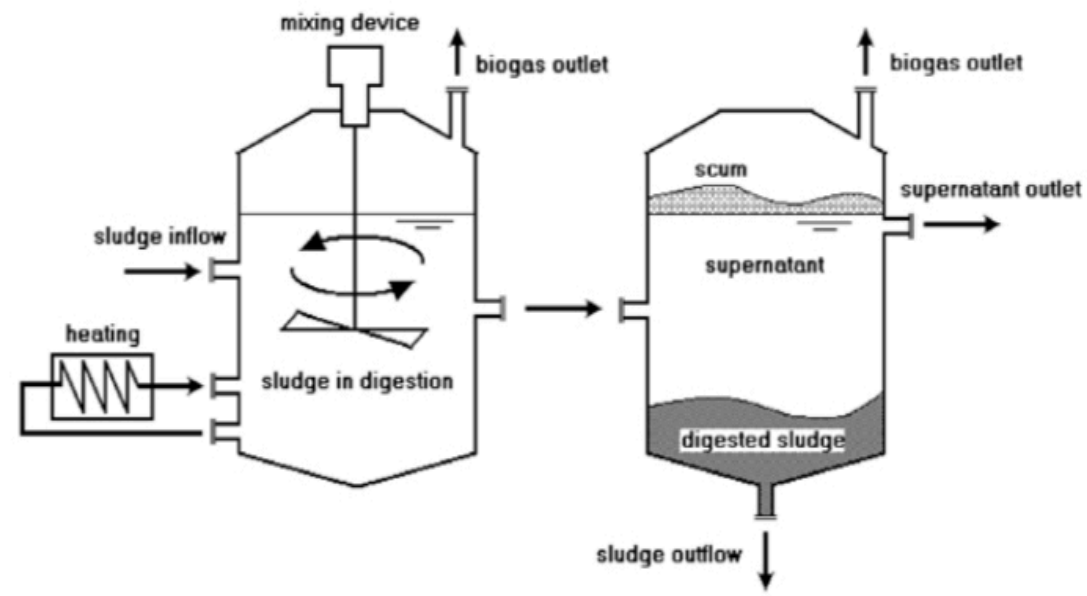

Figure 19 Two-stage high rate digester 
Sometimes the two stage digesters are designed for having the similar two tanks with the same properties so that any of the tank can be used for the primary functioning of the digester in the production of the sludge and the storage.

\section{Classification based on biomass}

\subsection{Attached growth anaerobic digester}

The anaerobic digesters designed to treat the waste where the bacteria and microorganisms are attached to the media in the digester. The media forms the base to treat the waste overflowing it. This type of digesters is very efficient in the removal of BOD, nitrification and denitrification. Rotating biological contactors and trickling filter are the most commonly used attached system of anaerobic digesters. Raw waste water is initially treated before following this system in order to remove the bigger particles and the wreckage flotation as the particles can plug the filter. (WATER PROGRAMS, n.d.)

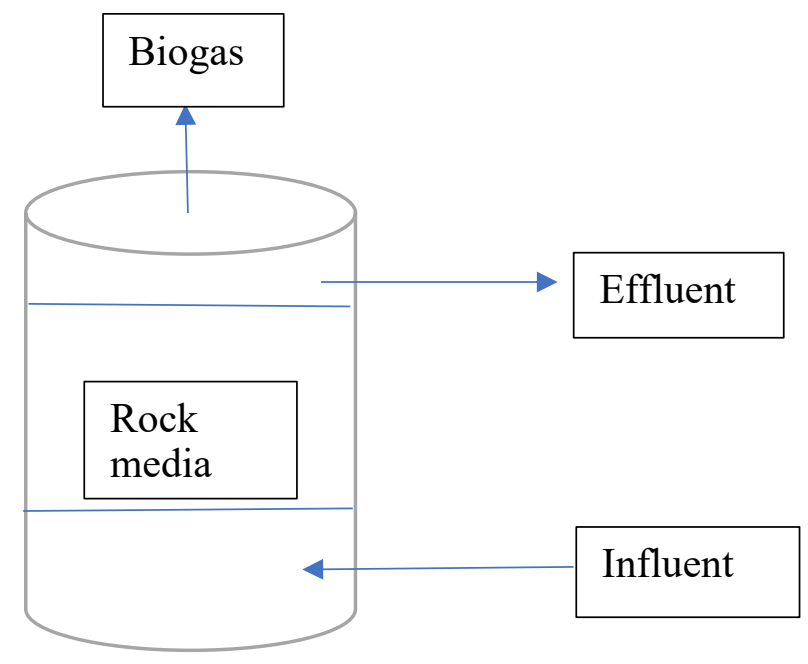

Figure 20 Attached growth digester system

This type of digester work as a flow-through functioning, wastewater passing through an attached film bacterial growth, the wastewater that has soluble particles being absorbed by the 
bacteria in the digester and the insoluble being adsorbed by the surface. The flow is generally from the bottom of the digester to the top of the digesters where the effluents are drawn out with the release of biogas. The advantages and drawbacks of attached system of anaerobic digester are mentioned below:

\subsubsection{Advantages of attached growth anaerobic digester}

- The mode of operation is easy.

- High efficiency.

- Low energy consumption.

- Low maintenance.

\subsubsection{Disadvantages of attached growth anaerobic digester}

- Require very large volume of area.

- Sometimes odor problems are of concern.

\subsection{Suspended growth anaerobic digester}

The suspended growth anaerobic digesters are designed for the flow of waste through and along the microorganisms in the digesters floating around settling down the wastewater. There is a continuous action taking place in the digesters for the mixing inside the tank (figure 20). Generally, the larger particles stay in the tank while the smaller once are washed away due to the flow.

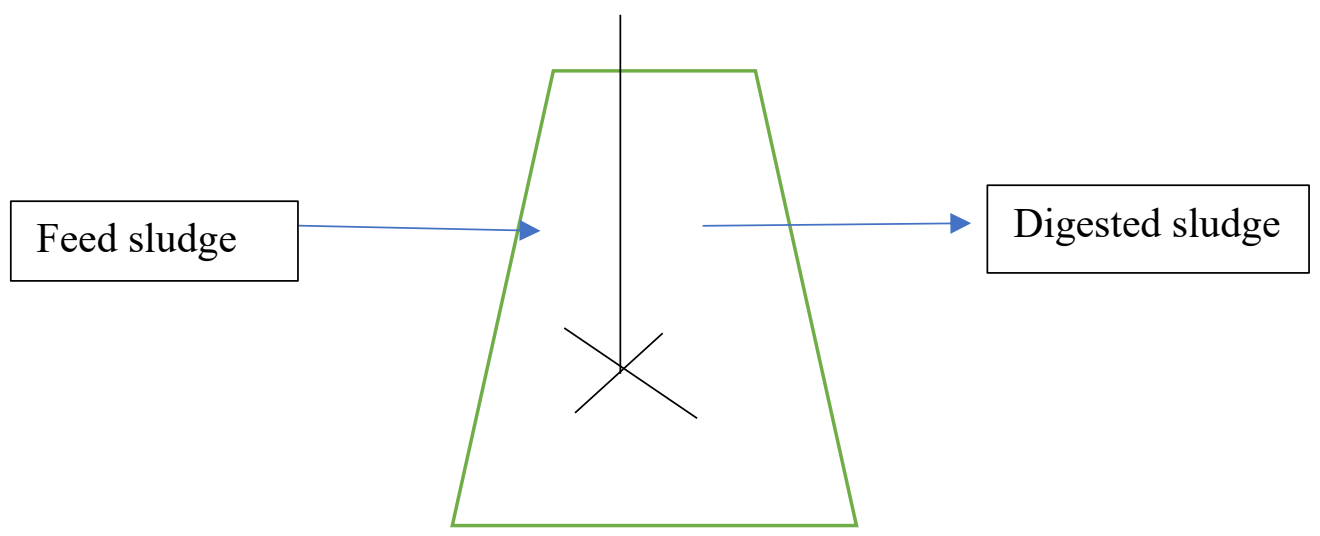

Figure 21 Suspended growth digester 
Suspended growth anaerobic digesters are generally adopted at the municipal wastewater treatment plants where the degradation of both primary and secondary sludge is required. The process of anaerobic digestion results in the formation of layers in the tank.

There is a development of biofilm layer around the larger particles in the tank. Effluent coming out of the tank can be reused in certain conditions to provide the required upward flow in the tank. The longer HRTs., are used in the designing of total mixed digesters where the feedstock can be introduced anytime during the continuous or in between the process. Few useful aspects and drawbacks are mentioned below:

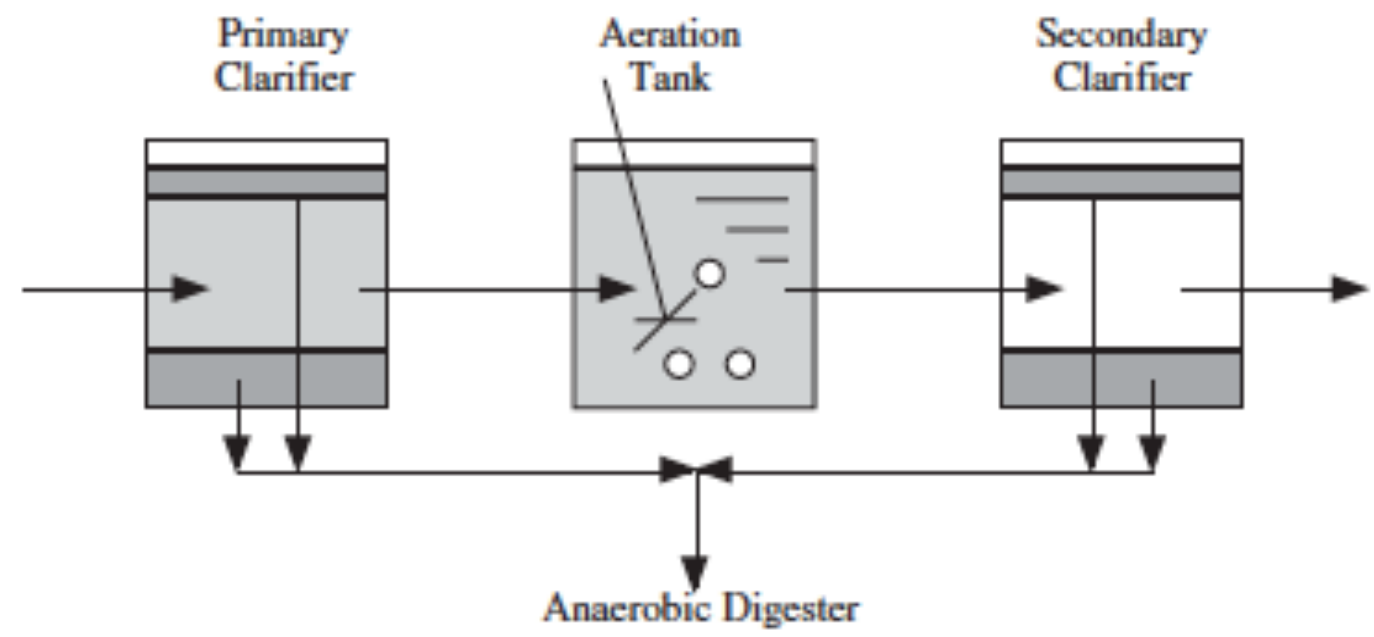

Figure 22 Primary and secondary sludge treatment at the municipal wastewater treatment

plant

\subsubsection{Advantages of suspended growth anaerobic digester}

- Distribution of nutrients is uniform.

- $\mathrm{pH}$ and temperature are moderate and uniform.

- Well suited for the treatment of colloidal, particulate and soluble wastes.

7.2.2 Disadvantages of suspended growth anaerobic digester.

- Volume of the digester requirement is very large. 
- Due to the loss in particulate matter the efficiency in the treatment can be reduced.

\section{Different conventional systems of anaerobic digestion technology}

The anaerobic digestion system can be classified into three systems which are:

- Farm-Based Systems

- Food Processing Systems

- Centralized Systems

\subsection{Farm-Based Systems}

This type of system in generally designed for the farm locations where manure from the farms are the source to the digesters. This type of system is very simple and easy to operate with least material requirement. This system is very widely practised in the regions of Europe and North America. The major output from this system is heat or energy (production of electricity).

A study says that in America there is production of more than 600 million $\mathrm{kWh} / \mathrm{year}$ of energy from the farm-based systems.

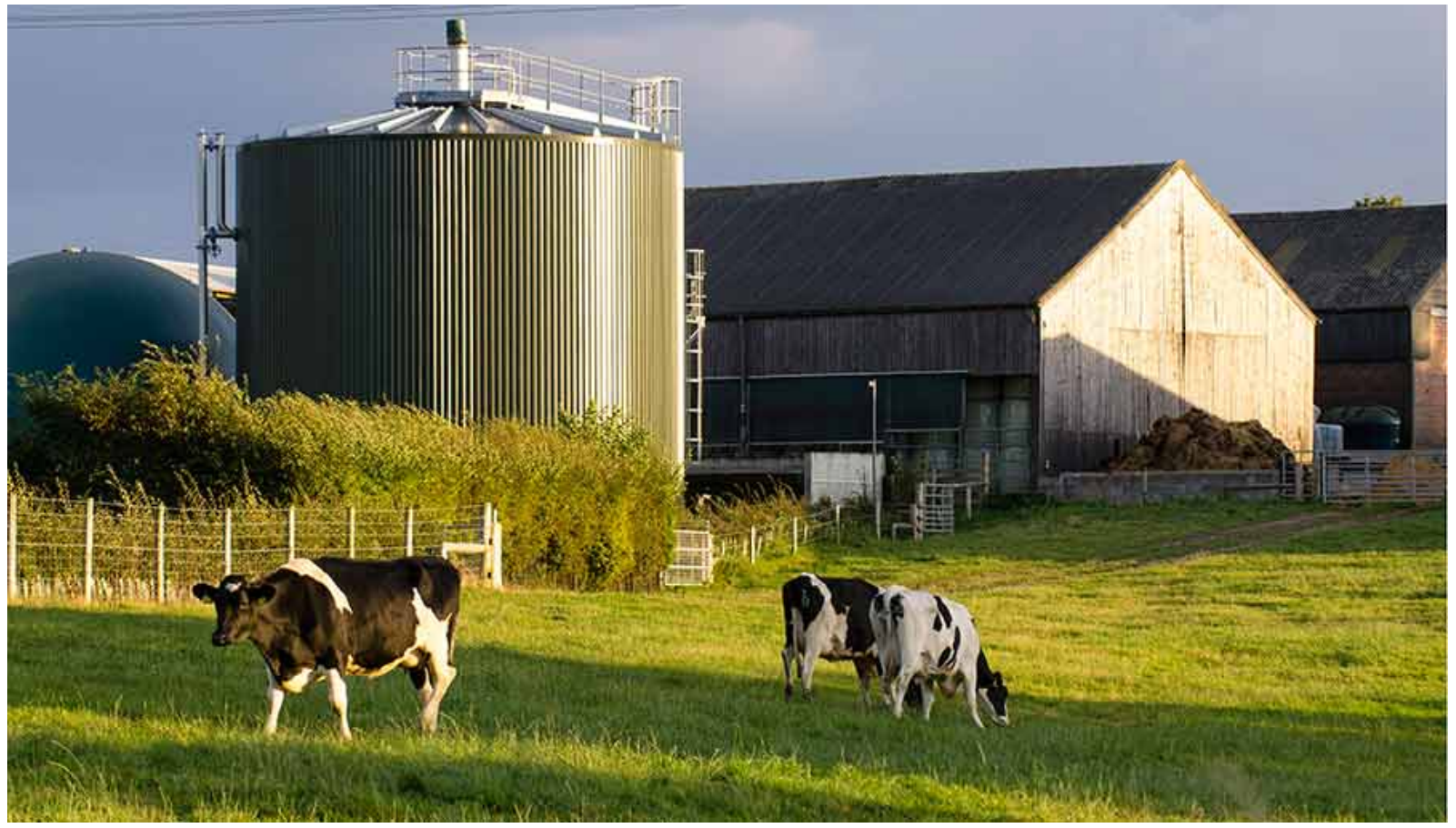

Figure 23 Farm based digestion plant. (Goldstein, 2013) 


\subsection{Food Processing Systems}

This system works similar to that of Farm-based system where the major output is heat or energy (production of energy). This system is also very efficient on removing the organic composition the wastewater. This system of digesters is designed for the removal of organic matter in the waste and produce energy.

\subsection{Centralized Systems}

Centralized systems work both for the farm-based and food processing in common. The major output of this type of system is production of heat energy that can be utilized for commercial purpose or for the residences. This system is widely practised in Europe than any other part of the world.

\subsection{Examples of most commonly used anaerobic digesters}

\subsubsection{Covered lagoon}

The digesters which are completely covered by the cove resulting in the production of methane from the treatment that happens in the ponds or lagoons. This system is of low maintenance and easy operation. The digesters have low hydraulic retention time with greater organic loading rate. The lagoons act both as treatment plants and as storage system. (HAMILTON, 2012) (BUILD-ABIOGAS-PLANT, n.d.).

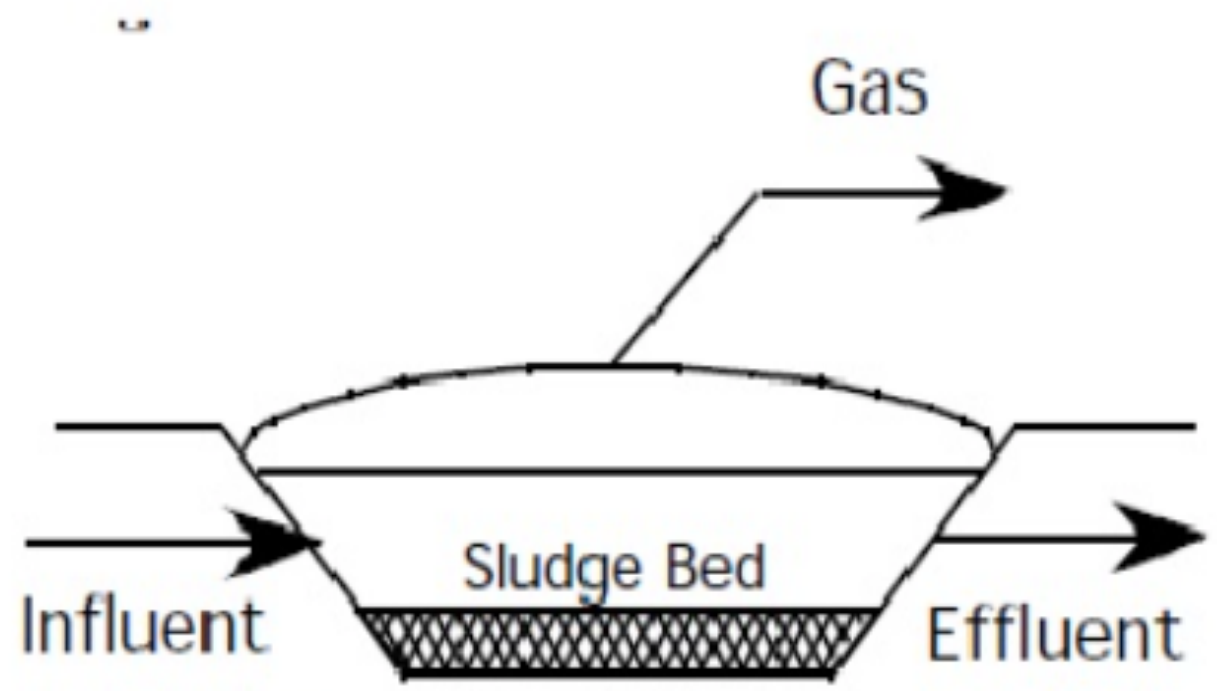

Figure 24: Schematic representation of covered lagoon (Abedeen, 2010) 
Table 6 Design criteria

\begin{tabular}{|c|c|}
\hline Depth of the lagoon & Minimum $5 \mathrm{~m}$ \\
\hline Detention time & $8-40$ days \\
\hline Loading rate & $0.3-0.8 \mathrm{~kg} \mathrm{BOD} / \mathrm{m}^{3} \cdot \mathrm{d}$ \\
\hline Pre - treatment & Removal of grease \\
\hline Sludge removal & Separate sludge pipe \\
\hline
\end{tabular}

\subsubsection{Advantages of covered lagoons}

- Low operational and construction costs.

- Less odor emission.

- Simple design and operation.

- Less mixing activity is required.

\subsubsection{Disadvantages of covered lagoons}

- Sludge accumulation.

- Scum accumulation.

- Generation of irritation odor. 


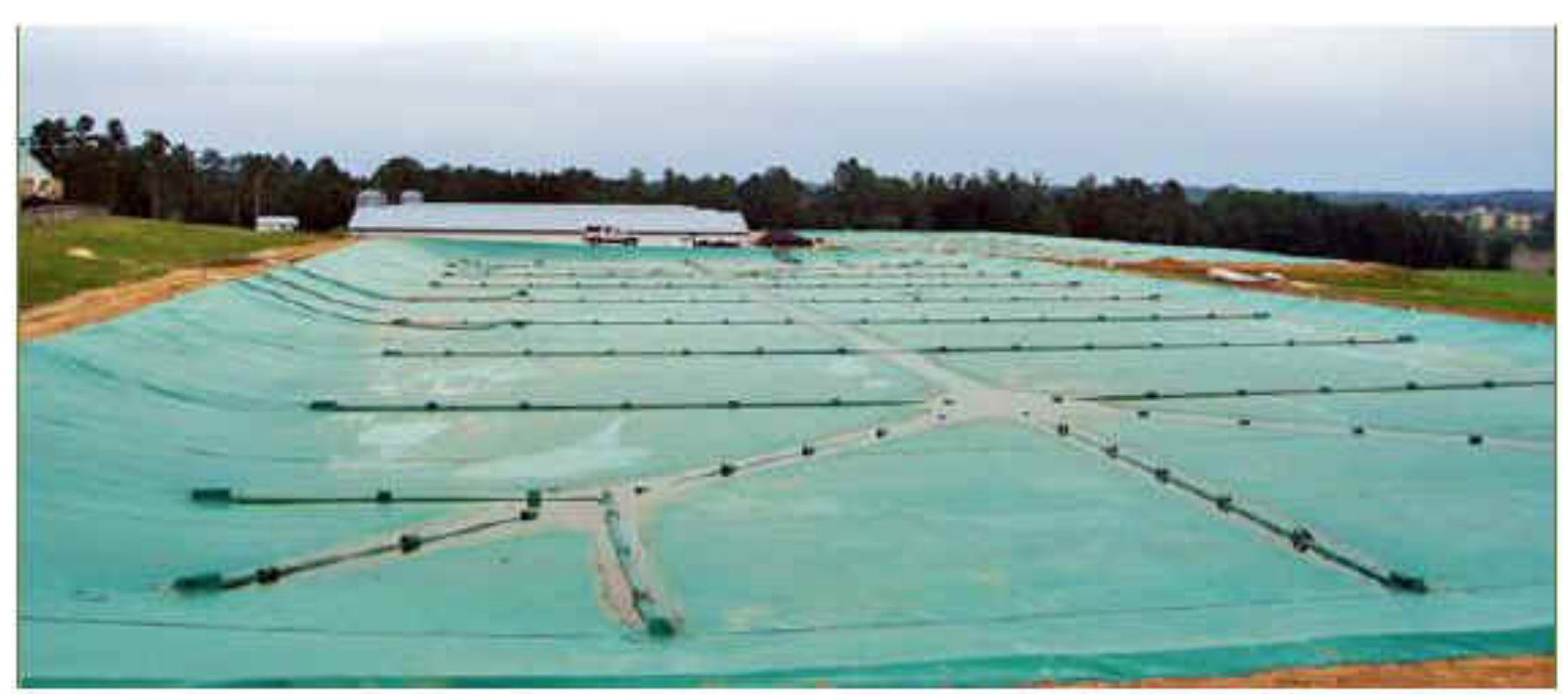

Figure 25: Covered lagoon (Plug flow digester, 2007)

Covered lagoons generally consist of: solid separator that is used in the separation of the solid in the waste for the treatment, not necessarily one lagoon as it may have more than one lagoon and a biogas utilization arrangement. For a covered lagoon to be very efficient it is seen that if it has two connected lagoons for the initial operations then followed by a separate biogas production system. (RCM technology, n.d.)

The brief design criteria summary of the covered lagoons is given in the table 9. One of the greatest known covered lagoon digesters is been in operation since 1982 at Royal Farms in Tulare, CA. The farm is adopted with the three-cell lagoon system and also has a water flush manure organization system. The digester is been efficient in the reduction of pathogens and odor with good amount of biogas production.

\subsubsection{Complete Mix Digester}

The complete mix digester is a tank used in the treatment of wastewater where the mass to be treated is heated and constantly or intermediately mixed with the set of active microorganisms in the tank. Equal amount of liquid flows out of the tank with the incoming liquid to the tank. The retention time the digester various with the temperature in the tank and is considerably less for the thermophilic digesters. The process may require more than one set of tanks depending on the amount of loading. (HAMILTON, 2012) 
The major composition of the complete mix digester includes: a mixing tank, tanks designed for heating the materials and biogas recovery organization, an effluent storage system and a biogas operation arrangement.

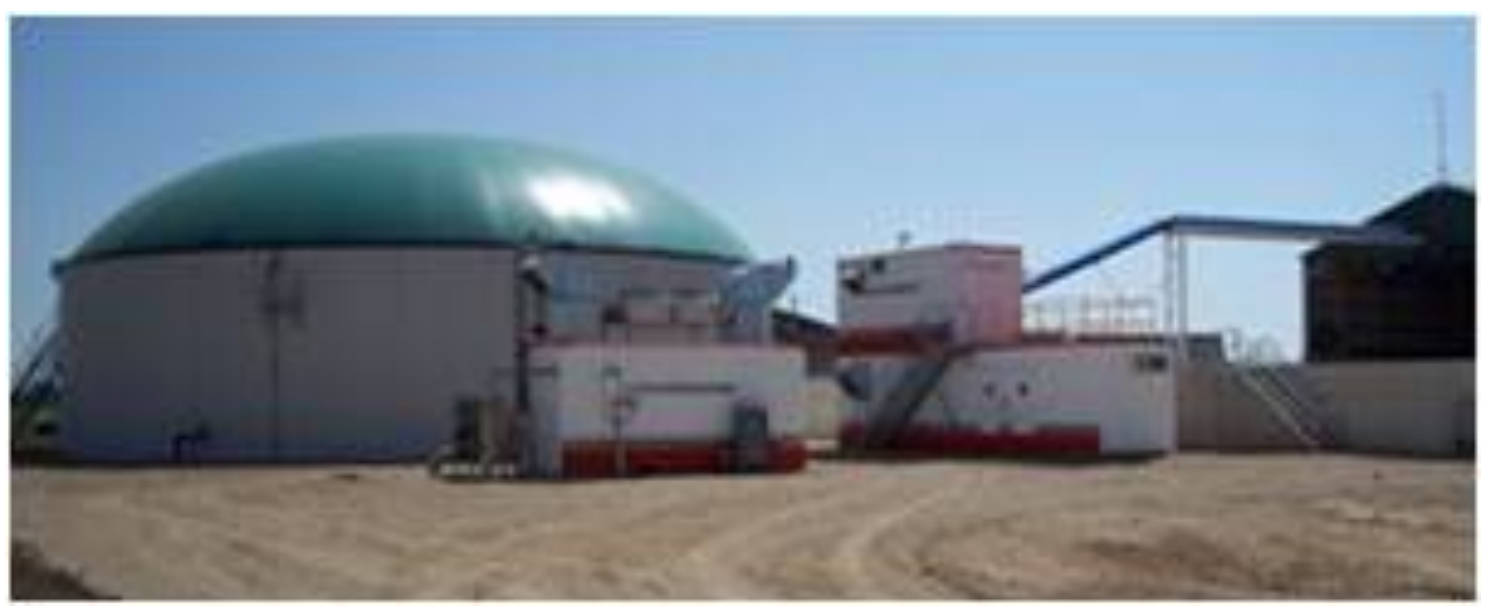

Figure 26 Complete mix digester (Doug.Hamilton)

The size of the digester varies depending on the amount of solid concentration. If the digester is generally large that means the lower solids are in the digesters which means the large digester is required for retaining microbes for about 15 to 25 days of time period. 


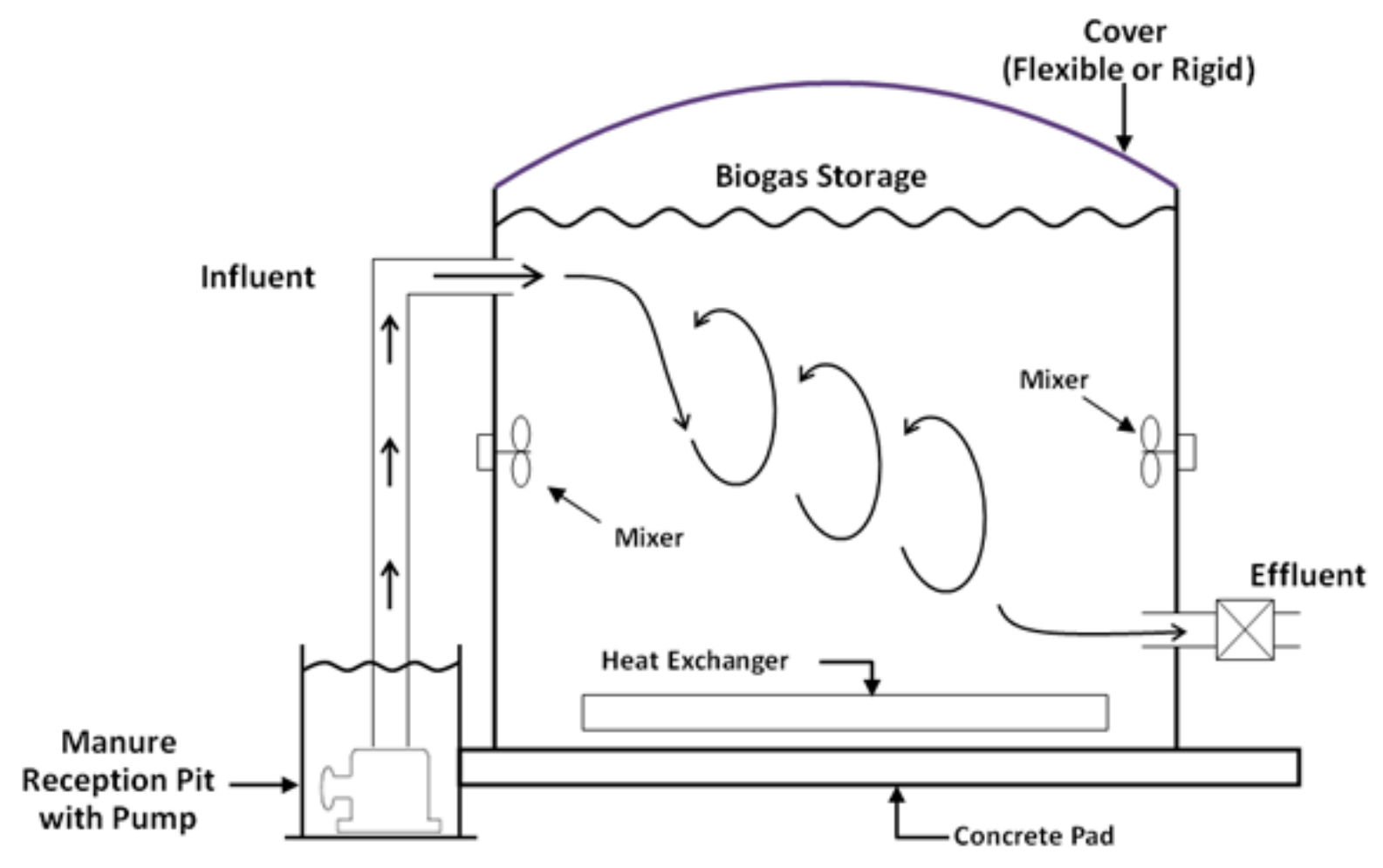

Figure 27: Complete mix digester (Plug flow digester, 2007)

\subsubsection{Plug Flow digester}

The plug flow digester works with same mechanism as of complete mic digester where the flow of material is equal with the outlet flow leaving the digester (figure 22). In plug flow digester there is no or very less settlement of the particles from the waste at the bottom of the tank as the waste or manure to be treated is thick enough preventing the settlement. When the phase of mixing is required, there is generally very minimal mixing happening in the tank due to which the manure flows as a plug and deriving its name as plug flow digester. The necessary retention time for plug flow digester is between 10 to 20 days. The configuration of plug flow digester is a simpler tank having five times the length than the width. (HAMILTON, 2012) 


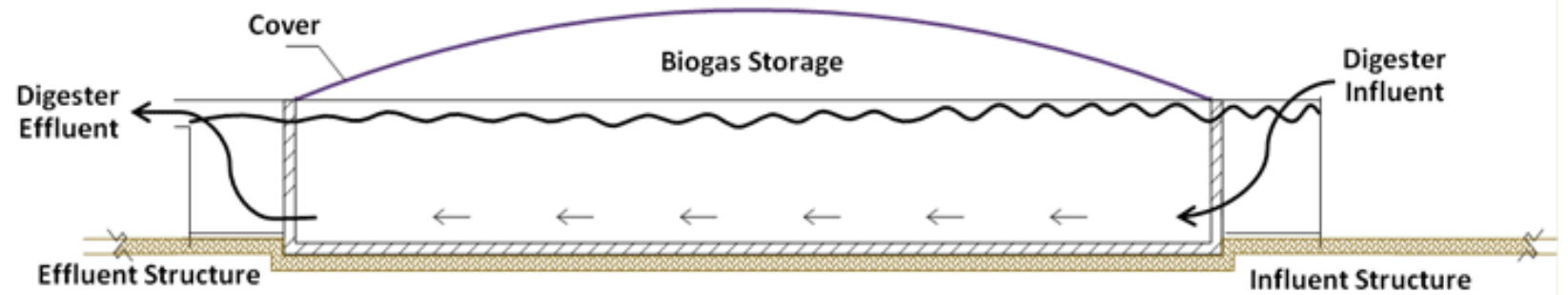

Figure 28: Plug flow anaerobic digester (Plug flow digester, 2007)

A study by (Lusk, 1998) shows that there have been several successful operating plug flow digesters around the globe, the one major operating digester is located in Godley, TX at the Kirk Carrell Diary which is functioning from the fall 1998 with the production of $20,000 \mathrm{ft}^{3} / \mathrm{d}_{\text {biogas }}$ say about $60 \%$ methane content. The main output of the energy is used for the production of electricity. From a hypothetical study based on the plug-flow digesters by (Lusk, 1998) certain estimations have been derived and mentioned below:

\begin{tabular}{|lr|} 
Methane & 182 \\
Carbon Dioxide & 302 \\
Grit & 103 \\
Fiber & 1,422 \\
Filtrate & $\underline{8,215}$ \\
TOTAL & 10,224 \\
\hline
\end{tabular}

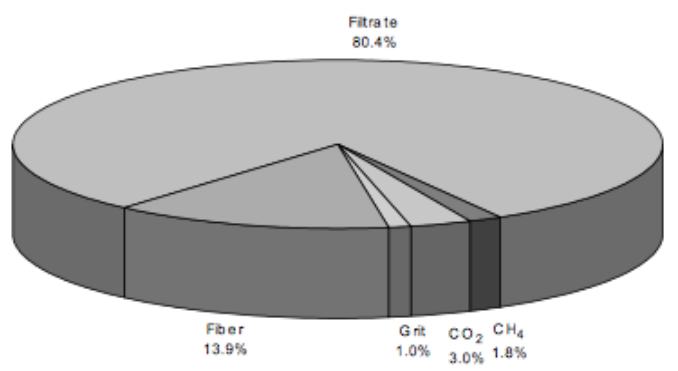




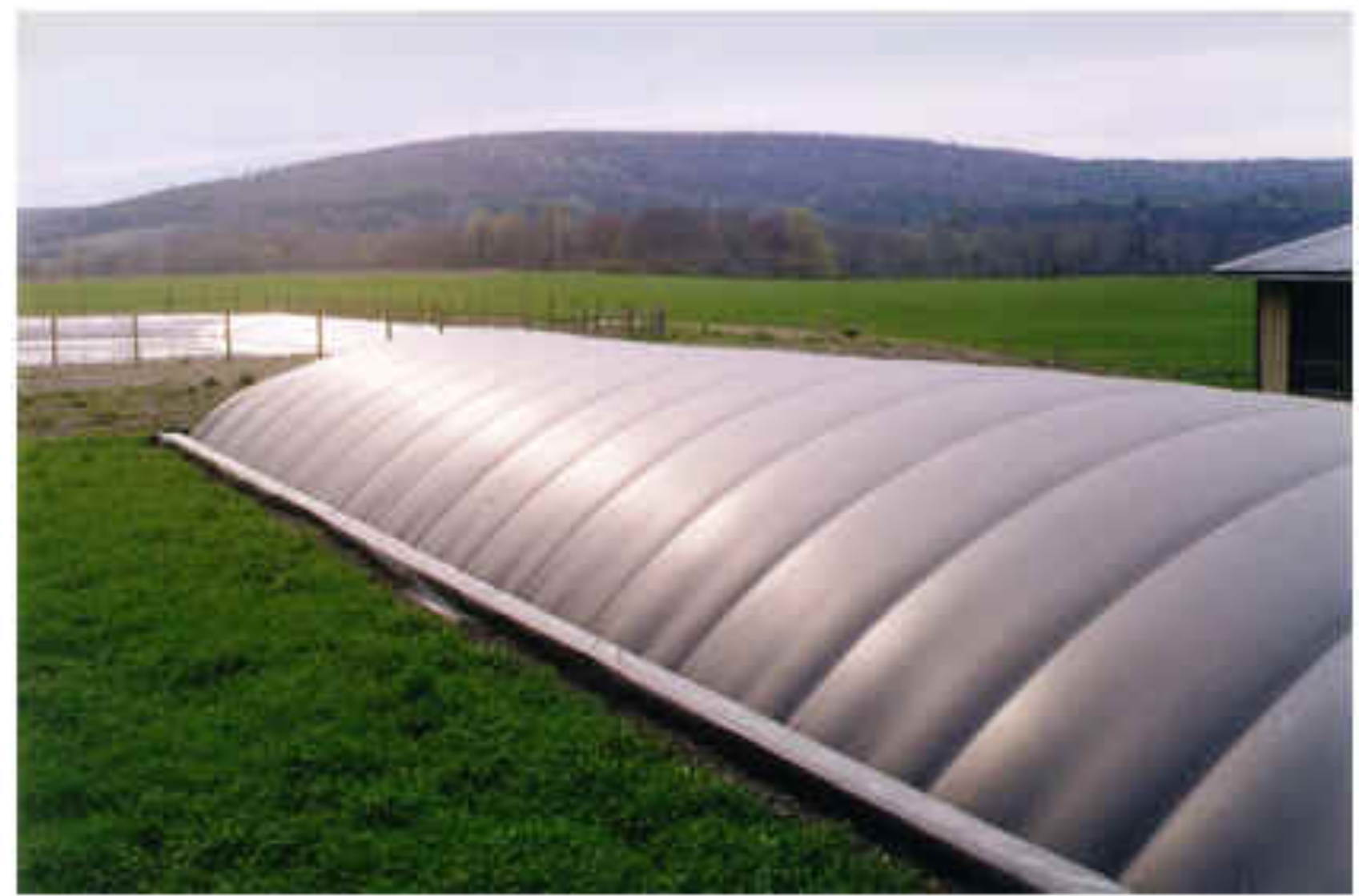

Figure 29: Plug flow digester (Plug flow digester, 2007)

\subsubsection{Fixed Film Digester}

Fixed film digester is an anaerobic column tank which has fixed film installed in the tank for the growth of microbes required for the production of methane from the anaerobic process. Sometimes this type of digester is referred as attached growth digester. The means by which the growth of bacteria occurs is referred as biofilm. The retention period required for fixed film digester is about less than five days. (ARITA, 2013)

The type of wastewater that can be treated by the fixed film anaerobic digesters are groundwater that needs or requires a method of treatment, industrial wastewater with high concentrations of nitrogenous compounds and carbohydrates. 


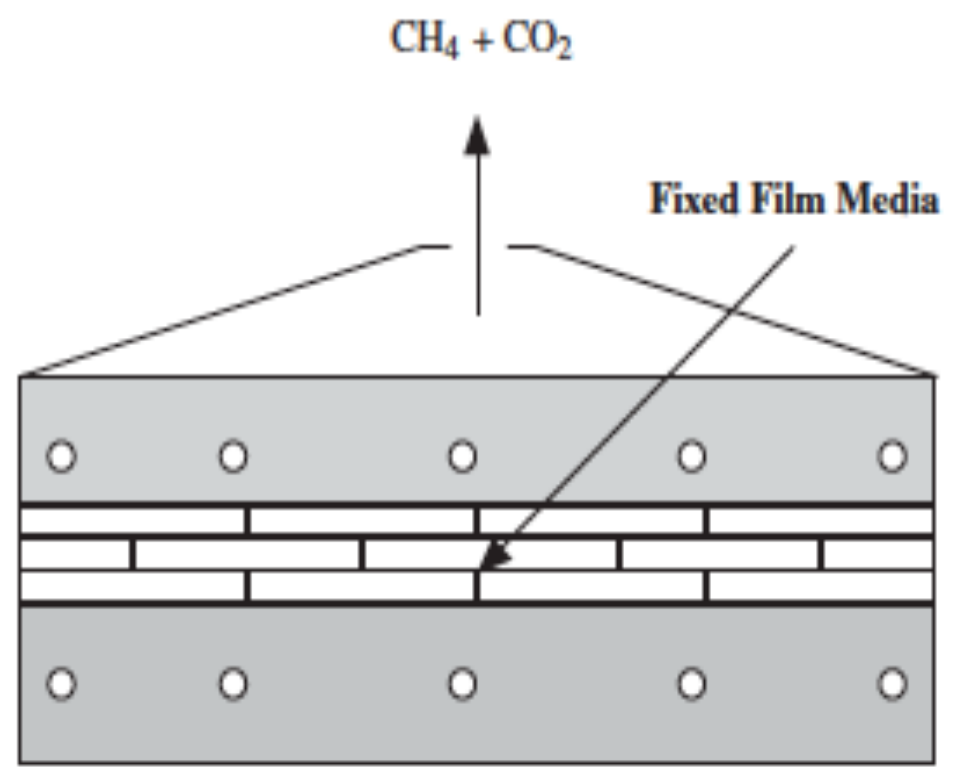

Figure 30: Fixed film anaerobic digester

Table 7 list of some of the fixed film anaerobic digester.

\begin{tabular}{|c|}
\hline Fixed - film digesters \\
\hline Baffled reactor \\
\hline Thin - film bioreactor \\
\hline Fully packed up flow \\
\hline Hybrid flow \\
\hline Fluidized - bed reactor \\
\hline Expanded bed \\
\hline Modular \\
\hline
\end{tabular}




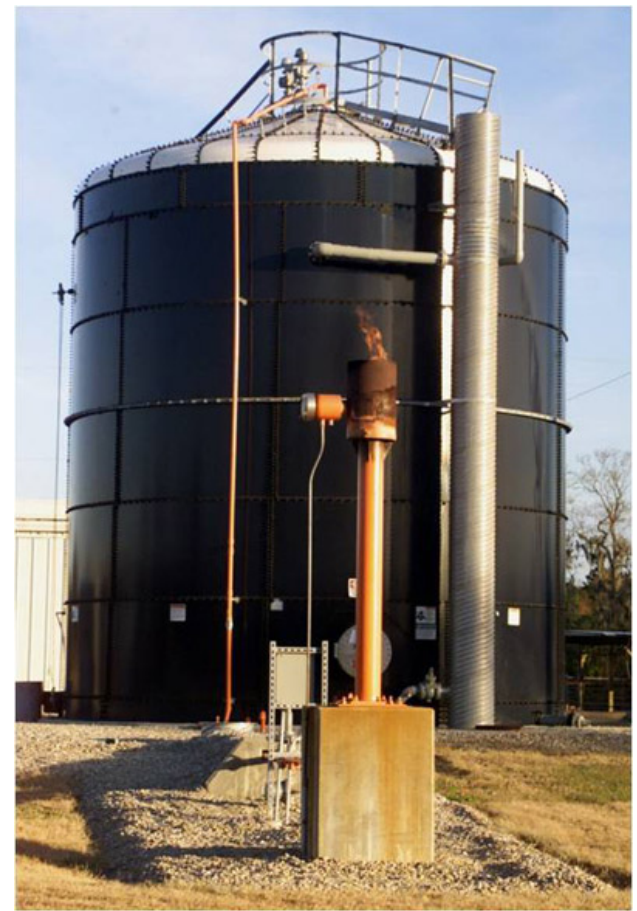

Figure 31 Fixed film digester (HAMILTON, 2012)

The following chart shows the data about what kind of digesters work in the American region and their respective number of plants.

Table 8 Digester plants across America

Solids Typical hydraulic Digester type content (\%) retention time (days) Temperature

\begin{tabular}{|c|c|c|c|}
\hline Covered lagoon & N/A & $30-40$ & Psychrophilic \\
\hline Plug flow & $11-14$ & $10-25$ & $\begin{array}{l}\text { Mesophilic ( } 68-113^{\circ} \mathrm{F} \text {, } \\
\text { optimally around } \\
86-100^{\circ} \mathrm{F} \text { ) or } \\
\text { thermophilic }(122- \\
\left.131^{\circ} \mathrm{F} \text { up to } 158^{\circ} \mathrm{F}\right)\end{array}$ \\
\hline Complete mix & $5-10$ & $10-25$ & $\begin{array}{l}\text { Mesophilic or } \\
\text { thermophilic }\end{array}$ \\
\hline Fixed film & $<1$ & A few days & $\begin{array}{l}\text { Mesophilic or } \\
\text { thermophilic }\end{array}$ \\
\hline
\end{tabular}




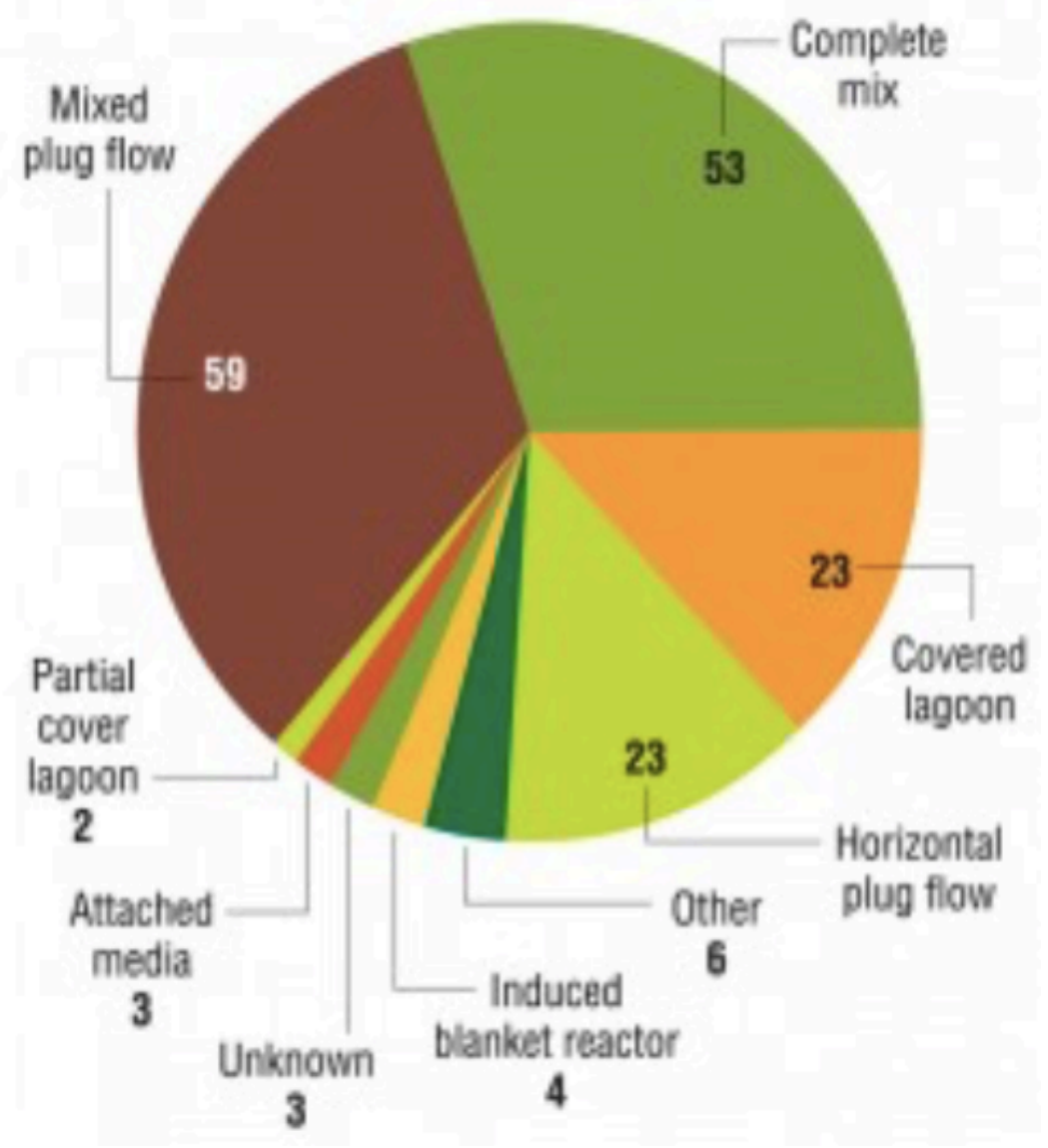

Figure 32: Operating digesters in the American region

\subsubsection{Anaerobic membrane bioreactor}

This method is proven to be one of the latest technologies in treating the wastewater. In this type of system, the anaerobic digestion process is accompanied with the separation membrane installed resulting in the maximum output results of removal of organic load and greater production of biogas that's again utilized in the production of electricity.

1. Cost effective

- Energy saving costs

- No primary treatment required

- Minimal disposal cost

- Eliminate chemical usage 
2. Environmental advantages

- Residue free of TSS

- Very less output footprint

- Development in improving the global water security

3. Processing benefits

- Can withhold very high amount of organic loading rate

- Both pre-treatment and post-treatment requirements is minimum.

- Digestion of large quantity of materials.

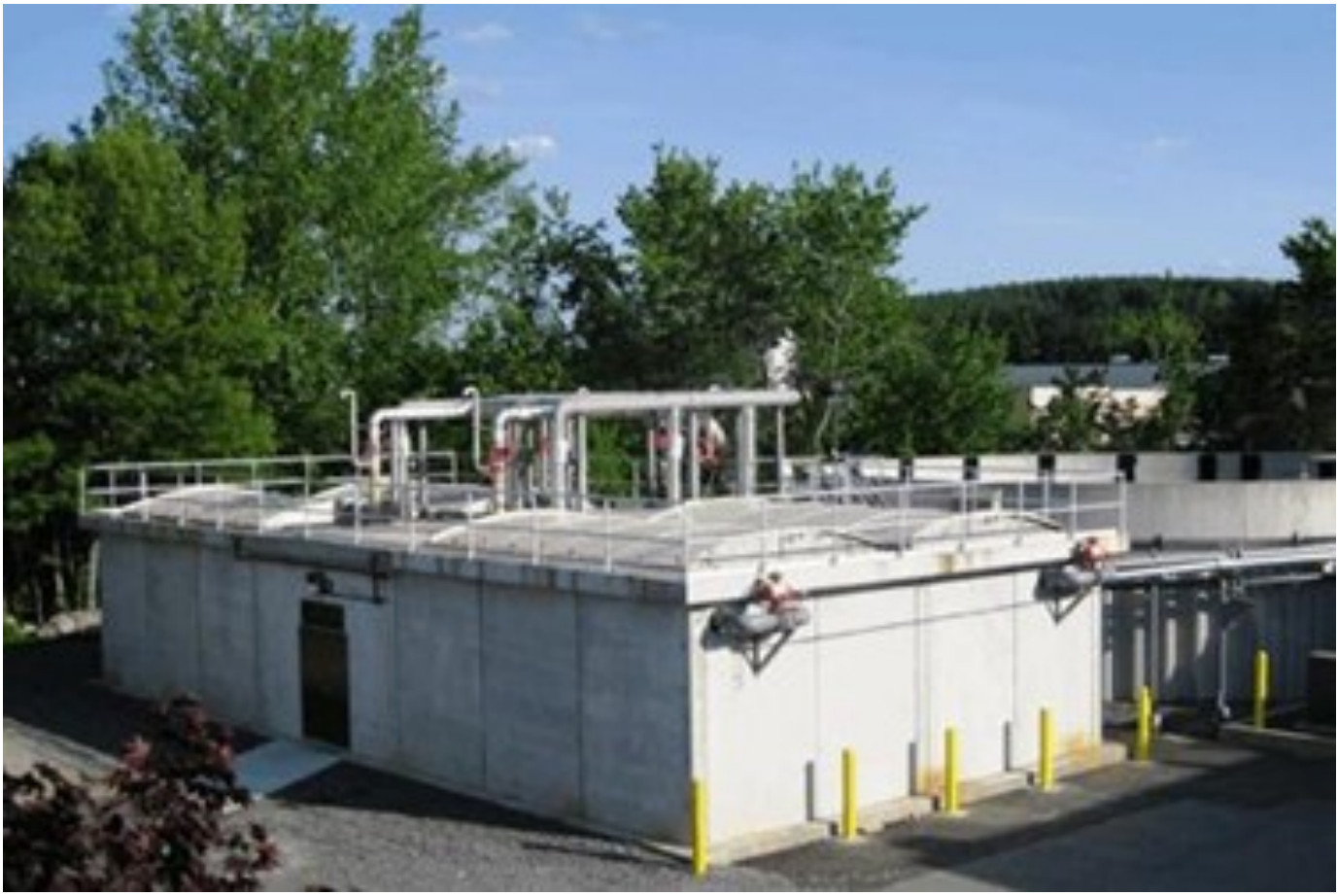

Figure 33 Anaerobic membrane bioreactor

\section{Anaerobic digestion technology around the world.}

\subsection{United States of America}

USA has the maximum potential in the production of biogas due to availability of large volume of pig farms and dairy farms. Approximately it is estimated that there are around 2,000 working condition anaerobic digestion sites in the country, which is one of the largest to have in the 
western part. On-farm the estimation is around two hundred and twenty functional plants, being mounted every year and can produce up to 400,000 MWhe every year. The data says that there is around $11,500 \mathrm{kWh}$ usage of the electricity annually, which means the anaerobic digestion plants can serve up to 36,000 households per year.

In the 2013, American Biogas Council estimated that, there are about 1,238 plants across the existing wastewater treatment plants in the US, and 1,054 of them which produce considerable amount of energy that can be utilized and around 621 across the landfill sites. (PULLEN, 2015)

\subsection{China}

Based a study, it was found that a family of five, in Guangxi state of China approximately used about 2,100 kg of firewood annually. When there was an act of incorporating the anaerobic digestion plants per household for every 125 families it was noticed that there was massive cutdown on the usage of firewood and development in the surrounding forest area. By 2010, it was seen that there were about five million of such plants across the country in operation and about one million on a large scheme plant. (PULLEN, 2015)

\subsection{International prominence of Anaerobic Digestion Technology}

Anaerobic digestion technology in action:

Europe - 302, Germany - 92, North America - 13, Canada - 6.

In progress:

North America - 20, Canada - 4.

Farm anaerobic digesters in action:

Europe - 2429, Germany - 1900, United States of America - 201, Canada - 100. (Haanstra)

European countries have the majority of the running anaerobic digester technology out of which the maximum is worked on the farms of Germany comprising mainly of dairy farms. Next to Germany, its Italy and furthermore (figure 34). 
Table 9 Top ten states for electricity generation by adopting anaerobic digestion technology (Market oppurtinities for biogas recovery systems at U.S. livestock facilities, 2011)

\begin{tabular}{|c|c|c|c|c|c|}
\hline State & $\begin{array}{c}\text { Number of } \\
\text { Candidate } \\
\text { Farms }\end{array}$ & $\begin{array}{c}\text { Methane } \\
\text { Emissions } \\
\text { Reductions } \\
\text { (Thousand } \\
\text { Tons) }\end{array}$ & $\begin{array}{c}\text { Methane } \\
\text { Production } \\
\text { Potential } \\
\text { (billion } \mathrm{ft}^{3} \text { / } \\
\text { year) }\end{array}$ & $\begin{array}{c}\text { Energy } \\
\text { Generation } \\
\text { Potential } \\
\text { (Thousand } \\
\text { MMBtu/ } \\
\text { year) }\end{array}$ & $\begin{array}{l}\text { Electricity } \\
\text { Generation } \\
\text { Potential } \\
\text { (Thousand } \\
\text { MWh/year) }\end{array}$ \\
\hline \multicolumn{6}{|l|}{ Swine Farms } \\
\hline lowa & 1,997 & 301 & 21.5 & 19,818 & 1,829 \\
\hline North Carolina & 939 & 203 & 13.2 & 12,145 & 1,121 \\
\hline Minnesota & 707 & 63 & 7.3 & 6,726 & 621 \\
\hline Illinois & 350 & 39 & 4.3 & 3,936 & 363 \\
\hline Missouri & 154 & 34 & 3.5 & 3,265 & 301 \\
\hline Indiana & 296 & 31 & 3.5 & 3,208 & 296 \\
\hline Oklahoma & 56 & 51 & 3.4 & 3,164 & 292 \\
\hline Nebraska & 177 & 27 & 3.2 & 2,942 & 272 \\
\hline Kansas & 80 & 22 & 2.3 & 2,161 & 199 \\
\hline Texas & 10 & 25 & 1.6 & 1,516 & 140 \\
\hline $\begin{array}{l}\text { Remaining } 40 \\
\text { States }\end{array}$ & 830 & 109 & 10.6 & 9,828 & 907 \\
\hline SubTotal & 5,596 & 905 & 74.4 & 68,710 & 6,342 \\
\hline \multicolumn{6}{|l|}{ Dairy Farms } \\
\hline California & 889 & 341 & 27.9 & 25,729 & 2,375 \\
\hline Idaho & 203 & 99 & 8.9 & 8,257 & 762 \\
\hline New Mexico & 110 & 64 & 5.3 & 4,930 & 455 \\
\hline Texas & 155 & 66 & 5.0 & 4,644 & 429 \\
\hline Wisconsin & 251 & 41 & 4.5 & 4,178 & 386 \\
\hline Washington & 125 & 35 & 3.4 & 3,183 & 294 \\
\hline Arizona & 54 & 44 & 3.1 & 2,851 & 263 \\
\hline Michigan & 107 & 26 & 2.9 & 2,661 & 246 \\
\hline New York & 111 & 18 & 2.1 & 1,915 & 177 \\
\hline Colorado & 54 & 22 & 2.0 & 1,889 & 174 \\
\hline $\begin{array}{l}\text { Remaining } 40 \\
\text { States }\end{array}$ & 588 & 152 & 14.6 & 13,473 & 1,243 \\
\hline SubTotal & 2,645 & 908 & 79.9 & 73,709 & 6,803 \\
\hline U.S. Total & 8,241 & 1,813 & 154 & 142,419 & 13,144 \\
\hline
\end{tabular}


Head California Dairy farm with Covered Lagoon Digester

\begin{tabular}{l|c|c}
\multirow{4}{*}{ NPV } & Full Income & Electricity Only \\
\cline { 2 - 3 } IRR & $\$ 36,075$ & $(\$ 23,476)$ \\
SPP & $11.8 \%$ & $6.2 \%$ \\
CCF & 6.2 years & 83 years \\
& $\$ 200,987$ & $\$ 93,419$
\end{tabular}

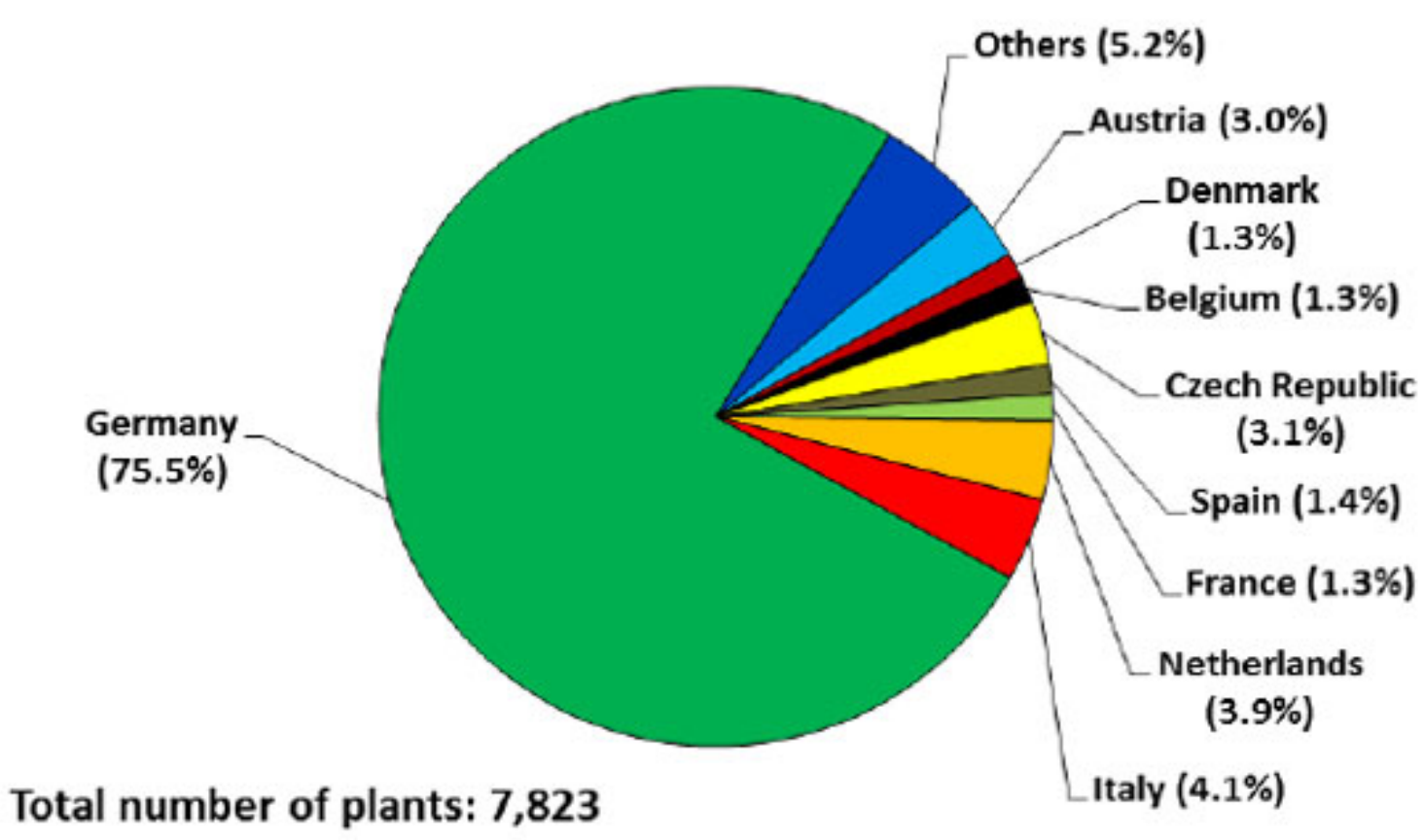

Figure 34: Digester plants in the EU countries.

Head south Dakota farm with plug-flow digester (Lusk, 1998)

\begin{tabular}{|l|c|c|}
\multirow{2}{*}{ NPV (\$) } & Full Income & Electricity Only \\
\cline { 2 - 3 } IRR $(\%)$ & $\$ 18,124$ & $(\$ 44,646)$ \\
SPP (years) & $10.8 \%$ & $1.7 \%$ \\
CCF $(\$)$ & 6.4 years & 12.5 years \\
\hline
\end{tabular}


10 Case studies on full scale anaerobic digestion technology across the world

\subsection{Case study 1: AA Diary}

Name: AA Dairy Farms

Location: Candor, NY

Farm type: Dairy farm

Digester type: Plug-flow anaerobic digester with Hypalon cover material

In operation: since 1998

Biogas output: $42,000 \mathrm{ft}^{3} / \mathrm{d}$

Utilization of output biogas: production of electricity

Production of electricity: for 500 dairy cows, 43,000 - 455,000 kWh production is obtained

O \& M cost estimation annually: $\$ 15,000$ (Lusk, 1998)

\subsection{Case study 2: Cushman Dairy}

Name: Cushman Dairy Farm

Location: North Franklin, CT

Farm type: Dairy farm

Digester type: Complete mix digester

In operation: since 1997

Biogas output: $40,000-45,000 \mathrm{ft}^{3} / \mathrm{d}$

Utilization of output biogas: production of electricity

O \& M cost estimation annually: $\$ 10,000-\$ 12,000$ (Lusk, 1998)

\subsection{Case study 3: Julian Barham}

Name: Julian Barham Swine Farm

Location: Zebulon, NC

Farm type: Swine farm

Digester type: Covered lagoon

In operation: since 1998

Biogas output: $28,000 \mathrm{ft}^{3} / \mathrm{d}$ in summer 
Utilization of output biogas: production of electricity with reclaim of thermal power Electricity production: 325,000 - 355,000 kWh (Lusk, 1998)

\subsection{Case study 3: Darrell Smith Farm}

Name: Darrell Smith Poultry Farm

Location: Princeton, NC

Farm type: Poultry farm

Digester type: Complete-mix with metal tank

In operation: since 1998

Biogas output: $17,000 \mathrm{ft}^{3} / \mathrm{d}$ initially,

$42,000 \mathrm{ft}^{3} / \mathrm{d}$ mid-summer 1998

$O \& M$ cost estimation annually: $\$ 5,000$

Utilization of output biogas: production of electricity with reclaim of thermal power

Electricity production: 520,000 kWh estimate (Lusk, 1998)

\section{Scope of anaerobic digestion technology}

Anaerobic digestion technology is one of the rapidly emerging and considerably stable method that can be adopted in the production of renewable energy by treating the waste materials and wastewater from the environment. There has been a constant growth in the increase in number of anaerobic technologies from time to time in all parts of the world. A study in the American region shows how there is been increase in the anaerobic digestion projects between the period of 2000 - 2011. (Allison Costa, 2012)

\subsection{Anaerobic digestion technology as a mode of renewable energy}

As the human population is increasing rapidly, the need for renewable energy is also growing every year. The survey from an International Energy Agency says that the production of renewable sources is been increasing from time to time, 13\% in 2012 to $22 \%$ in 2013 . There is also a prediction for the figure to increase to $26 \%$ by 2020 . For the fulfillment of this demand anaerobic digestion technology could be the greatest method to be bought in action even more than the present running projects across the globe. Biomass makes one of the highest required 
renewable energy marking $9 \%$, which can more likely be obtained through the anaerobic digestion process in today's world.

Biogas is produced from the anaerobic digestion of waste materials. Biogas comprises of $60 \%$ methane that can be efficiently used to produce electricity or act as a fuel for the vehicles (cars, buses and trucks etc.) methane is produced from the anaerobic digestion of the waste generated from the sewage and food waste. The usage of non-renewable fuels can be replaced with the use of renewable fuels by using the methane produced from the biogas. It is the best alternate source of energy.

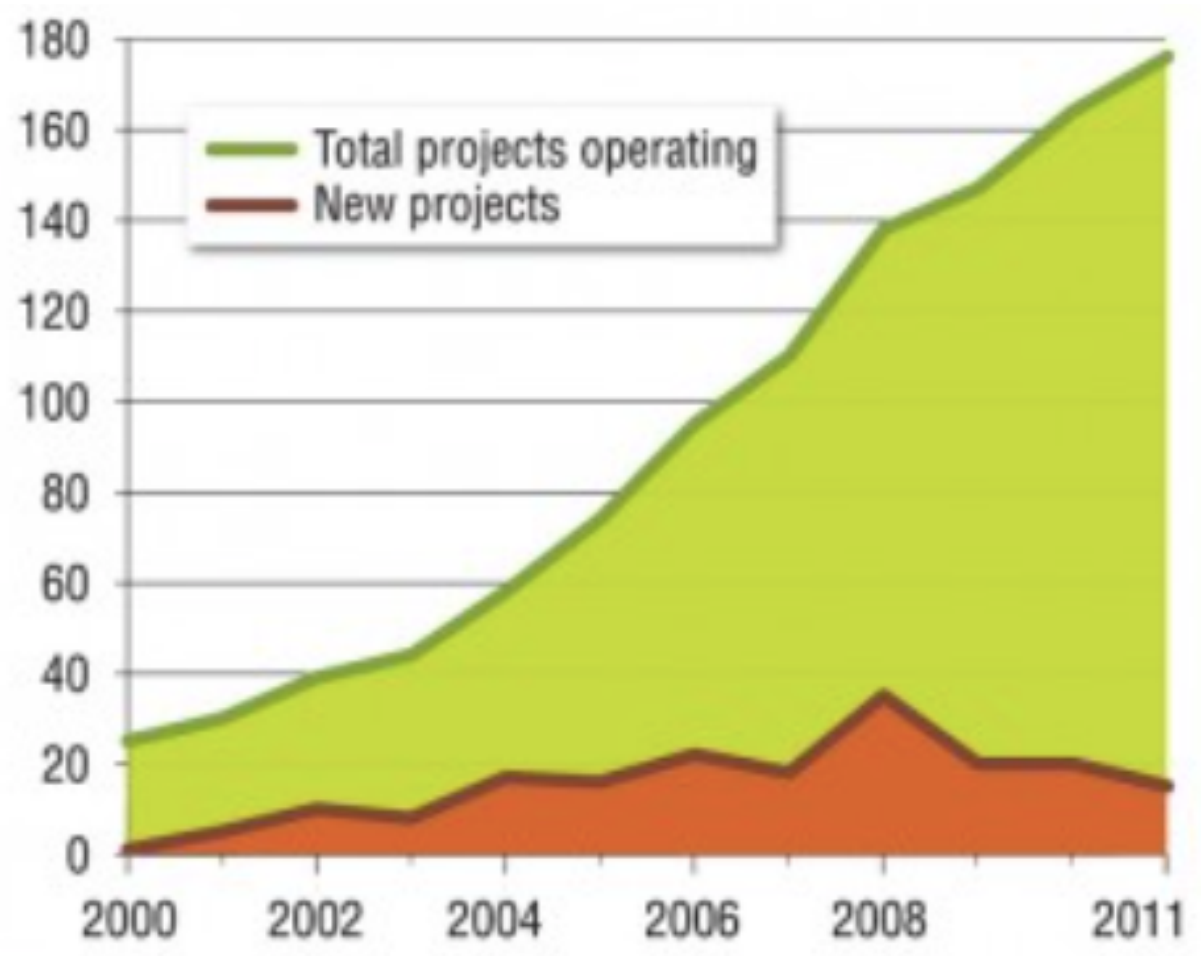

Figure 35: Anaerobic digestion plants 
Table 10: Anaerobic digester plants across U.S and Europe

$\begin{array}{llll}\text { Country Biosolids } & \begin{array}{l}\text { Biowaste / } \\ \text { Solid }\end{array} & \text { Agricultural } & \text { Industrial } \\ & \text { Industrial } & & \text { Wastewater } \\ & & \end{array}$

$\begin{array}{lllll}\text { Austria } & 100 & 3 & 100 & 25 \\ \text { Canada } & 50 & & & 13 \\ \text { Czech } & & & 10 & 4 \\ \text { Republic } & & 1 & 21 & 5 \\ \text { Denmark } & 64 & 49 & 1,500 & 3 \\ \text { Finland } & & 1 & 91 \\ \text { Germany } & & 4 & 50 & 2 \\ \text { Greece } & 2 & 2 & & 38 \\ \text { Italy } & & & 2 & 84 \\ \text { Netherlands } & & 1 & 94 & 5 \\ \text { Norway } & 17 & 4 & 6 & 3 \\ \text { Portugal } & & 11 & 3 & 27 \\ \text { Spain } & & 1 & 69 & 8 \\ \text { Sweden } & 134 & & 25 & 20 \\ \text { Switzerland } & 70 & & 28 & 26 \\ \text { U.K. } & 200 & & & 92 \\ \text { U.S.A. } & 1,600 & & & \end{array}$

Table 11 :Top ten states for electricity generation by adopting anaerobic digestion technology (Market oppurtinities for biogas recovery systems at U.S. livestock facilities, 2011)

\section{Anaerobic digestion technology in Canada.}

\subsubsection{Location: Southern Alberta farms}

The \$30-million project of the three jointly functioning anaerobic digesters near the Lethbridge works successively and efficiently. The biogas is obtained from the three collective digesters that is then used as a fuel to produce abundant amount of electricity. 
The digester plant working is owned together by a biogas plant that is based in Ontario called as planet, St. Catharines, and Alberta based ECB enviro North America Inc. The project is run all together in the name of Lethbridge Biogas LP.

The plant is capable of producing about $2.8 \mathrm{MW}$ of power that is being openly available in the market for the purchase. It is estimated that in the coming couple of years the output would be increased by $50 \%$ and produce $4.2 \mathrm{MW}$. The thermal energy generated at the plant is 100,000 gigajoules.

The plant is designed to accumulate nearly 100,000 tonnes of raw supply every year among which about $50 \%$ is obtained from the localities of the Alberta province. The majority of the supply comes from the dairy farms suitable for wet anaerobic digestion technology. The plant is mainly designed for the liquid manure hence not suitable for the dry anaerobic technology. The storage ability of the three-digester plant is designed in a way to hold up to two million liters of feedstock (Kryzanowski, 2014)

\subsection{Canadian anaerobic digestion technology organic processing status:}

1. Municipal anaerobic digestion plants in process

- Disco Road plant, Toronto, ON

- Harvest power high solids anaerobic digestion plant, Richmond, BC

- Harvest power anaerobic digestion plant, London, ON

- Georgian Bluffs/Chatsworth

\subsubsection{Disco Road Plant, Toronto}

Project development features:

- This project is owned by City of Toronto and maintained by Veolia Canada and Partner Group; CCI BioEnergy Inc. and BTA International.

- The type of waste treated at this plant is residential and commercial waste, source separated organic material and Curbside collected every week.

- The capacity of the plant initially was 75,000 metric tonnes per year operated in two shifts for five days in a week. (Toronto Disco Road-Canada, n.d.) 


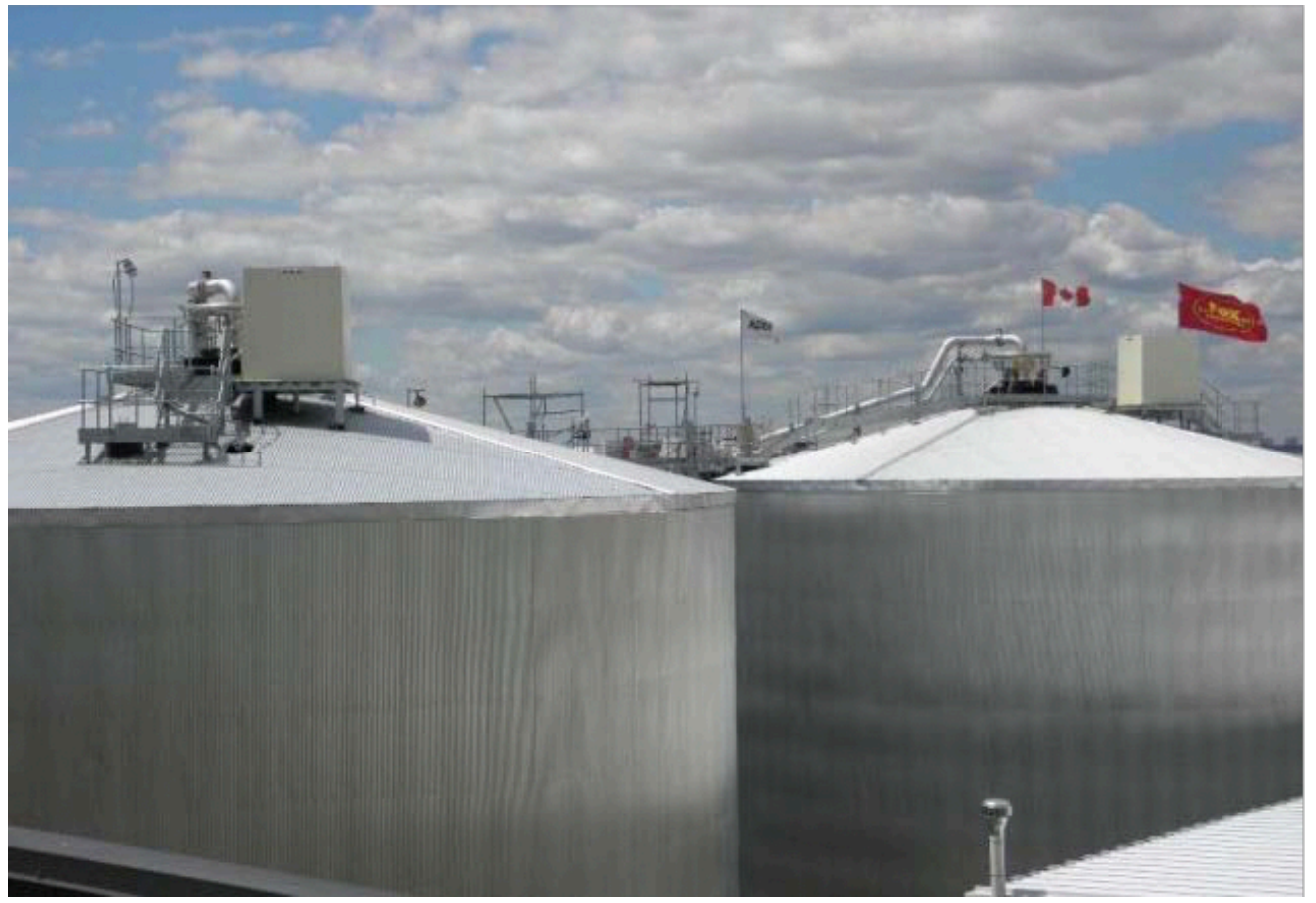

Figure 36 Disco Road plant, Toronto

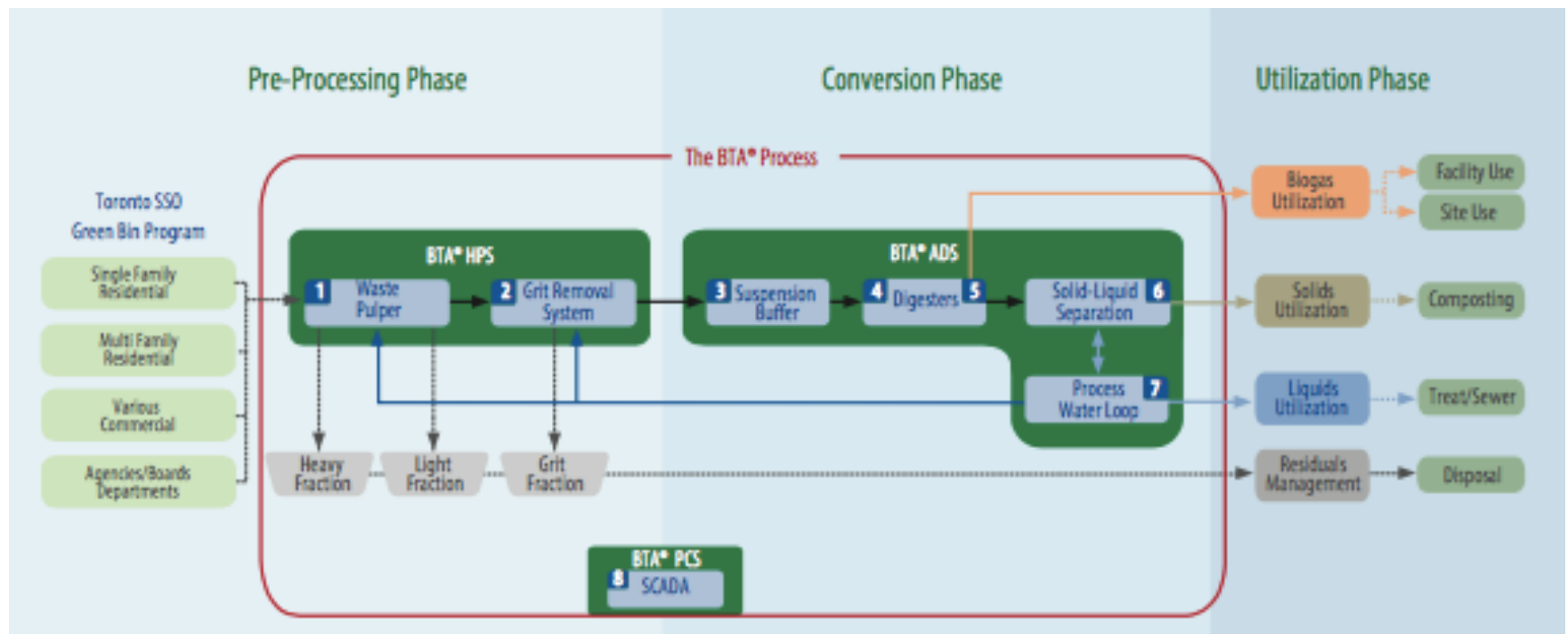

Figure 37 Disco Road organic Processing Facility

2. Municipal anaerobic digestion plants in development stage

- CRD Biofuel

- Edmonton organics AD 
- Surrey Biofuel (Haanstra)

There are several technologies or systems of anaerobic digestion in Canada accounting to the present day, in particular Ontario has two main types of technologies in practice for a very long period of time which are, plug flow digester and completely mixed digester. the output from both the type of technologies throughout the province is mainly used in the production of electricity, fuel and natural gas for the farms and the residences.

Feed-In Tariff Program and Hydro One Net Metering Program have been considered in Ontario for selling or substituting the present electricity where the energy from biogas can be used in the production of electricity.

\subsection{The future of anaerobic digestion technology in Canada:}

With the increase in the population and pollution every day there is also increase in the demand for a stable environment which is causing an aspiration to do the GREEN activity, which this type of technology totally justifies.

The rapid increase in pollution leaves a great amount of carbon footprint in the environment which is believed to reduce by adopting anaerobic digestion technology, it also increases the credible carbon potential.

Approximately, 25 million tons of solid waste in produced by residential and nonresidential bases in Canada, among which the majority of the waste production comes from Ontario. Ontario generates about 9 million tons of the solid waste as known by the data provided by Government of Canada (2016). It is already noticed that most of the municipality are considering the idea of anaerobic digestion as a better alternative to put in action and get benefited with its great applications. Day to day there is been a development in the field of anaerobic digester plants to maximize the efficiency of the plants and several improvements are coming as an output of the development. (Haanstra) 


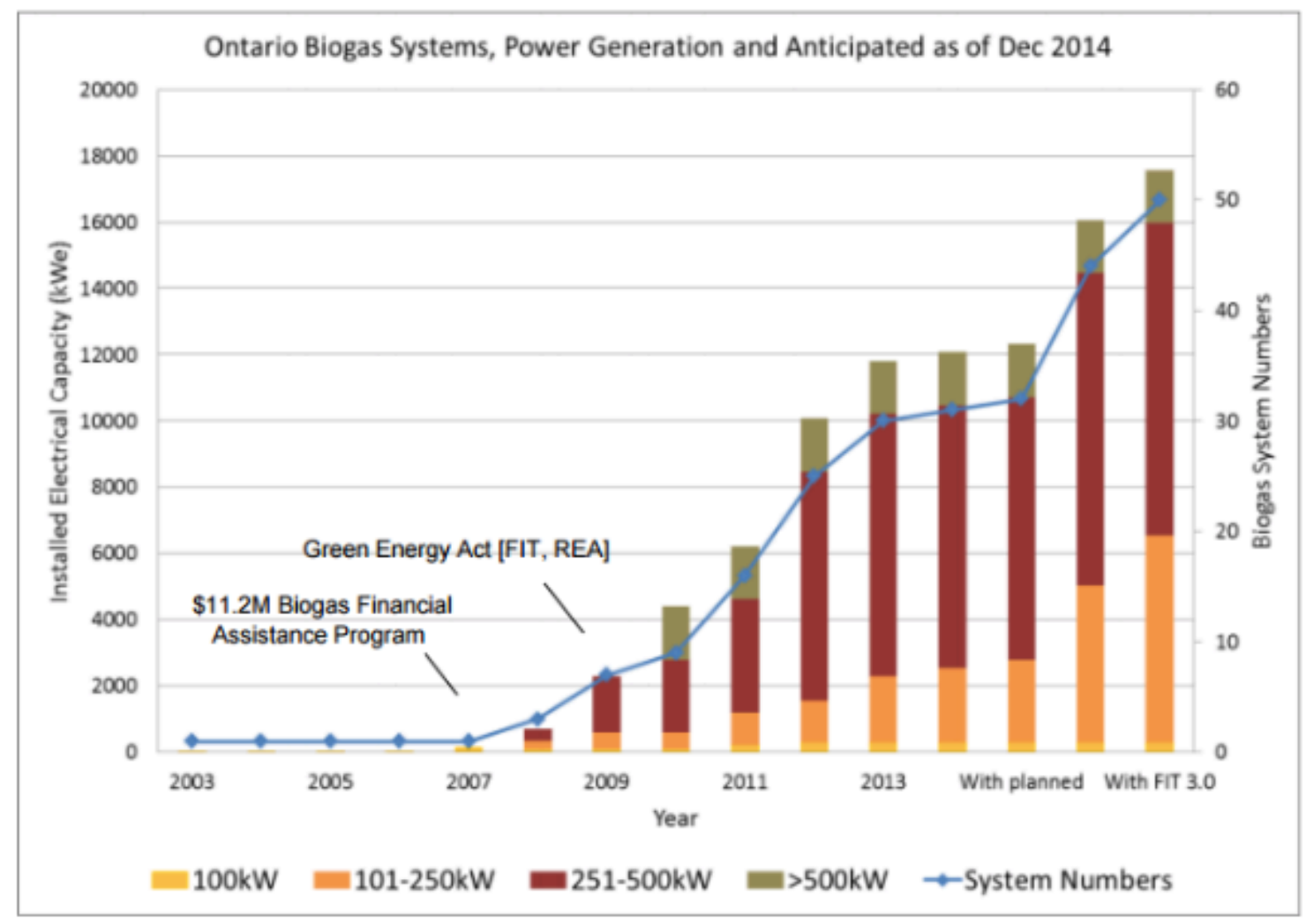

Figure 38 System growth

\section{Challenges faced while planning the Anaerobic Digestion technology}

There are certain things to be considered while planning and installing the anaerobic digestion plants which are as follows, (DeBruyn, 2007)

- Consent to admit resources

For any new project installing od anaerobic digestion need to obtain a certificate approved under the Environmental Protection Act or Nutrient management Strategy under the Nutrient Management Act.

- Consent to build the plant.

Building permit is one of the important things to start the project of anaerobic digesters.

- Insurance

One must be very well aware about obtaining the complete insurance covering for the whole digester technology plant. 
- Gathering all the necessary documents with the approval of utilizing the energy gained from the digesters.

\section{Advantages of Anaerobic digestion technology.}

- Production of renewable energy

Anaerobic digestion technology is one the best technologies to be proven as a source or mode of gaining back the renewable energy. Looking at the current situation of the world and the environment, we are in very much need of renewable energy which can be best obtained by this technology.

- A good functional plant can be constructed only in about a week time, thus can be installed very quickly when necessary.

- The least skilled labour and the materials are required to install a plant when needed in emergency.

- The variation in the technology makes it very smart and fascinating technology in the present world. (PULLEN, 2015)

- It was very much adaptable may it be the size, mode of working ability or designing when compared with the other methods of renewable energy source machinery methods.

- Widely accepted technology across the most of countries in the world.

- It is proven to be a reliable mode of renewable energy technology and very well functional when compared to other means.

- Can be adopted on both on large-scale and small-scale farms and households, hence making it very easy to adopt anywhere.

- No requirement of any kind of skilled labour or materials during the operation for years for small-scale or household.

- It is the most local form of technology that is available across every part of the world including rural areas.

- It is proven to be the ecologically strong recycling methods considered in present world and fight for better environment. 
- The release in the greenhouse gases can be considerably reduced with the adoption of anaerobic digestion technology. (J.B. Holm-Nielsen, 2009)

- Resourceful in the production or preservation of the fertilization which in turn can be used for several other applications.

- In comparison with the other means of technologies used for the renewable energy, anaerobic digestion technology is more economical and environmentally approachable.

- Most likely to be sustainable of organic waste materials. (Anaerobic Digestion )

- Better at maintaining the balance in the waste regulation when compared to other technologies.

\section{Limitations of anaerobic digestion technology.}

- There can be ammonia volatilization if there is no entrenched crusting shell in the digester tank.

- There is good possibility of stirring to happen if the manure is not impelled at the bottom of the digester. (J.B. Holm-Nielsen, 2009)

- If had to be adopted for the commercial purpose or at wastewater plants, it needs a huge amount of investment without knowing the outcome of the final results.

- If the technology is not efficient as required, can cause a severe odor issues that are not acceptable. (Radimin, 2015)

- The technology when used for the waste which is diluted, it is considered to be uneconomical due to requirement of greater volume in the digester tanks. (P.E.)

- Sometimes there is release of unacceptable smelling acids and abundant amount of hydrogen sulfide and ammonia nitrogen into the environment causing several harmful effects.

- If the residues or eliminated waste is not treated, it can cause the pollution to the surface and groundwater. (P.E.)

- Sometimes it is difficult to design as the requirement of suitable site cannot be fulfilled due to the opposition in neighboring public opinion for large scale plants. 
- For the technology to run smooth it is very much important that it has a reliable source of feedstock that is required for the operation.

- Sometimes there can be lack of investment as the commercial plants are very expensive. (Freya, 2015) 


\section{References}

(n.d.). Retrieved from BUILD-A-BIOGAS-PLANT: https://www.build-a-biogas-plant.com/coveredlagoon-digesters/

(n.d.). Retrieved from

https://floatingcovers.files.wordpress.com/2010/10/completemixdiagram2.gif

(n.d.). Retrieved from https://anaerobic-digestion.com/the-anaerobic-digestionprocess/thermophilic-anaerobic-digestion/

(n.d.). Retrieved from Anaerobic digestion.com: https://anaerobic-digestion.com/theanaerobic-digestion-process/thermophilic-anaerobic-digestion/

(n.d.). Retrieved from Anaerobic digestion.com: https://anaerobic-digestion.com/theanaerobic-digestion-process/thermophilic-anaerobic-digestion/

Abedeen, Z. (2010, August 04). Anaerobic Aerobic Digestion. Retrieved from slideshare: https://www.slideshare.net/zakiabedeen/anaerobic-aerobic-digestion

Allison Costa, C. V. (2012). Farm digester industry in america . Biocycle, 38.

Anaerobic Digester upset and troubleshooting. (n.d.). Retrieved from Aquafix: https://teamaquafix.com/anaerobic-digester-upset-troubleshooting/

anaerobic digestion. (n.d.). Retrieved from americanbiogascouncil.org: https://www.americanbiogascouncil.org/biogas_what.asp

Anaerobic Digestion . (n.d.). Retrieved from Biogas Renewable Energy : http://www.biogasrenewable-energy.info/anaerobic_digestion_advantages.html

APPLICATIONS, M. I. (n.d.). AMPC mla. Retrieved from https://www.ampc.com.au/uploads/cgblog/id299/Info-Sheet-for-CAL.pdf

ARITA, C. E. (2013). ANAEROBIC DIGESTION. Colorado.

Arita, C. E. (2013). anaerobic digestion comparision of manure leachate by high-rate anaerobic reactors. Colorado.

Biogas and anaerobic digestion. (n.d.). Retrieved from The ecoambassador: https://www.theecoambassador.com/images/Anaerobicsolutioncompressed.jpg 
Bouman, R. W. (2008). Benefits of thermophilic digestion at christchurch wastewater treatment plant. New Zealand.

Chaoran, L. (2015). wet and dry anaerobic digestion of biowaste and cosubstrates.

CHERNICHARO, C. A. (2007). Anaerobic Reactors .

Chunlan Mao, Y. f. (2015). Review on research achievement of biogas from anaerobic digestion. Renewable and Sustainable Energy Reviews., 540-555.

Covered lagoon digesters. (n.d.). Retrieved from Build-a-biogas-plant.com: https://www.builda-biogas-plant.com/covered-lagoon-digesters/

Doug.Hamilton. (n.d.).

Freya. (2015, february 24). RINOBS AD \& BIOGAS. Retrieved from rinobs.com: http://www.rinobs.com/anaerobic-digestion-pros-and-cons.html

GERARDI, M. H. (2003). In The Microbiology Of Anaerobic Digesters. Linden.

GERARDI, M. H. (2003). THE MICROBIOLOGY OF ANAEROBIC DIGESTERS. Pennsylvania: A John wiely \& sons, Inc,.

Goldstein, N. (2013). Agriculture Anaerobic Digestion in the U.s. Biocycle, 41-43.

Haanstra, J. H. (n.d.). Anaerobic digestion technology development .

HAMILTON, D. (2012, april 02). Types of Anaerobic Digesters. Retrieved from extension: https://articles.extension.org/pages/30307/types-of-anaerobic-digesters

J.B. Holm-Nielsen, T. A.-P. (2009). The future of anaerobic digestion and biogas utilization. Bioresource Technology, 5478-5484.

Jenicek, G. D. (2016). Thermophilic versus Mesophilic Anaerobic Digestion of Sewage Sludge: A comparative review. Bioengineering (Basel).

KHALID, A. (2011). The Anaerobic Digestion of Solid Organic waste. waste Management, 17371744.

Kryzanowski, T. (2014, March 18). Canada's largest biogas plant . Retrieved from Manure Manager: https://www.manuremanager.com/beef/canadas-largest-biogas-plant-15093

L. Przywara, B. M. (n.d.). Anaerobic treatment of municipal sewage in the psychrophilic conditions. Poland.

Lusk, P. (1998). Methane Recovery from Animal Manures. Washinton, DC. 
(2011). Market oppurtinities for biogas recovery systems at U.S. livestock facilities. EPA.

P. Vandevivere, I. D. (2002). Types of anaerobic digester for soild waste.

P.E., D. A. (n.d.). OVERCOMING THE LIMITATIONS IN ANAEROBIC DIGESTION OF DIARY WATSE. Retrieved from makingenergy.com: http://www.makingenergy.com/Overcomming\%20the\%20Limitations\%20of\%20Anaero bic\%20Digestion\%20for\%20Dairys.pdf

Plug flow digester. (2007). Retrieved from PlugFlowdigester.com: http://www.plugflowdigester.com

PULLEN, T. (2015). ANAEROBIC DIGESTION-MAKING BIOGAS-MAKING ENERGY. Routledge.

Pullen, T. (2015). case studies. In T. Pullen, Anaerobic digestion - Making Biogas - Making Energy : The Earthscan Expert guide. Routledge.

R. Waltenberger, R. K. (2013, August 14). Wet and dry anaerobic digestion processes. Retrieved from

http://www.valorgas.soton.ac.uk/Pub_docs/JyU\%20SS\%202013/VALORGAS_JyU_2013_ Lecture_12.pdf

Radimin. (2015, october 23). The Advantages and Disadvantages of Anaerobic Digestion vs Composting . Retrieved from ANAEROBIC-DIGESTION.COM: https://blog.anaerobicdigestion.com/anaerobic-digestion-vs-composting/

RCM technology . (n.d.). Retrieved from RCM digesters : http://www.rcmdigesters.com/rcmtechnology/covered-lagoon/

Staged Anaerobic Digestion. (n.d.). Retrieved from theecoambassador.com: https://www.theecoambassador.com/StagedAnaerobicDigestion.html

Toronto Disco Road-Canada. (n.d.). Retrieved from CCI Bio Energy: https://www.ccibioenergy.com/wp-content/uploads/2018/01/CCl-FactSheet_Disco_mar-2015_email.pdf

WATER PROGRAMS. (n.d.). Retrieved from SACRMAENTO STATE : http://www.owp.csus.edu/glossary/attached-growth-processes.php 
WESTERLING, K. (2014, March 05). WATER ONLINE. Retrieved from https://www.wateronline.com/doc/biological-treatment-suspended-growth-vsattached-growth-0001 